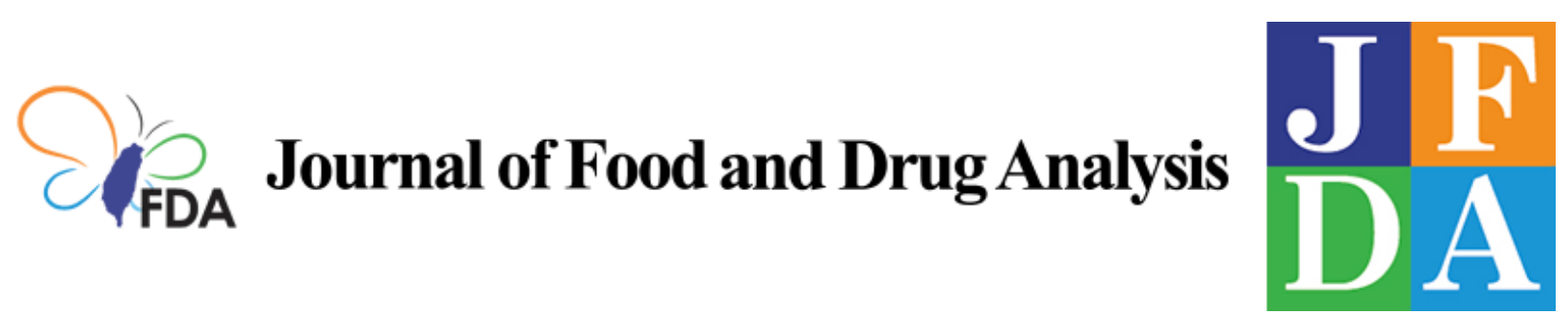

Volume 29 | Issue 1

Article 2

2021

\title{
The Bioactivities of Resveratrol and Its Naturally Occurring Derivatives on Skin
}

Follow this and additional works at: https://www.jfda-online.com/journal

Part of the Alternative and Complementary Medicine Commons, Medicinal Chemistry and Pharmaceutics Commons, Natural Products Chemistry and Pharmacognosy Commons, and the Pharmacology Commons

(c) (1) (9)

This work is licensed under a Creative Commons Attribution-Noncommercial-No Derivative Works 4.0 License.

\section{Recommended Citation}

Lin, Ming-Hsien; Hung, Chi-Feng; Sung, Hsin-Ching; Yang, Shih-Chun; Yu, Huang-Ping; and Fang, Jia-You (2021) "The Bioactivities of Resveratrol and Its Naturally Occurring Derivatives on Skin," Journal of Food and Drug Analysis: Vol. 29 : Iss. 1 , Article 2.

Available at: https://doi.org/10.38212/2224-6614.1151

This Review Article is brought to you for free and open access by Journal of Food and Drug Analysis. It has been accepted for inclusion in Journal of Food and Drug Analysis by an authorized editor of Journal of Food and Drug Analysis. 


\section{The Bioactivities of Resveratrol and Its Naturally Occurring Derivatives on Skin}

\section{Cover Page Footnote}

The authors are grateful to the financial support from Chang Gung Memorial Hospital (CMRPD1G0411-2) and Chi Mei Medical Center (108-CM-FJU-03). 


\title{
The bioactivities of resveratrol and its naturally occurring derivatives on skin
}

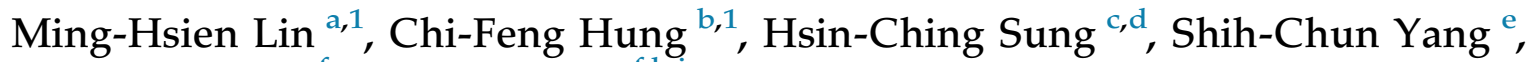 \\ Huang-Ping $\mathrm{Yu}^{\mathrm{f}, \mathrm{g}}$, Jia-You Fang ${ }^{\mathrm{f}, \mathrm{h}, \mathrm{i}, *}$
}

a Department of Dermatology, Chi Mei Medical Center, Tainan, Taiwan
b School of Medicine, Fu Jen Catholic University, Hsinchuang, New Taipei City, Taiwan
${ }^{c}$ Department of Anatomy, College of Medicine, Chang Gung University, Kweishan, Taoyuan, Taiwan
${ }^{d}$ Aesthetic Medical Center, Department of Dermatology, Chang Gung Memorial Hospital, Kweishan, Taoyuan, Taiwan
e Department of Cosmetic Science, Providence University, Taichung, Taiwan
${ }^{\text {f }}$ Department of Anesthesiology, Chang Gung Memorial Hospital, Kweishan, Taoyuan, Taiwan
g School of Medicine, College of Medicine, Chang Gung University, Kweishan, Taoyuan, Taiwan
h Pharmaceutics Laboratory, Graduate Institute of Natural Products, Chang Gung University, Kweishan, Taoyuan, Taiwan
${ }^{i}$ Research Center for Food and Cosmetic Safety and Research Center for Chinese Herbal Medicine, Chang Gung University of Science
and Technology, Kweishan, Taoyuan, Taiwan

Abstract

Resveratrol has been extensively reported as a potential compound to treat some skin disorders, including skin cancer, photoaging, allergy, dermatitis, melanogenesis, and microbial infection. There has been an increasing interest in the discovery of cosmetic application using resveratrol as the active ingredient because of its anti-aging and skin lightening activities. The naturally occurring derivatives of resveratrol also exert a beneficial effect on the skin. There are four groups of resveratrol derivatives, including hydroxylated compounds, methoxylated compounds, glycosides, and oligomers. The major mechanism of resveratrol and its derivatives for attenuating cutaneous neoplasia, photoaging and inflammation, are related with its antioxidative activity to scavenge hydroxyl radical, nitric oxide and superoxide anion. A systematic review was conducted to describe the association between resveratrol-related compounds and their benefits on the skin. Firstly, the chemical classification of resveratrol and its derivatives was introduced. In this review the cases which were treated for different skin conditions by resveratrol and the derivatives were also described. The use of nanocarriers for efficient resveratrol skin delivery is also introduced here. This review summarizes the cutaneous application of resveratrol and the related compounds as observed in the cell-based, animal-based and clinical models. The research data in the present study relates to the management of resveratrol for treating skin disorders and suggesting a way forward to achieve advancement in using it for cosmetic and dermatological purpose.

Keywords: Antioxidant, Nanocarriers, Naturally occurring derivatives, Resveratrol, Skin

\section{Introduction}

P olyphenols are the phytochemicals containing many bioactive compounds, mostly found in vegetables, fruits and soy [1]. These molecules can be classified into 5 major categories, including hydrobenzoic acids, hydroxycinnamic acids, flavonoids, stilbenes, and lignans [2]. Among these, resveratrol (3,5,4'-trihydroxystilbene) from the group stilbenes has gained lot of attention as it considered to be beneficial for human health. This compound was first isolated from the roots of Veratrum grandiflorum in 1940. It was initially characterized as a phytoalexin, providing defense against the attacks from insects and pathogens [3]. This natural phytoalexin is detected in more than 70 different plants such as grapes and berries, and is also found in human foods and in all kinds of

Received 29 May 2020; revised 19 August 2020; accepted 5 October 2020.

Available online 15 March 2021.

* Corresponding author: Pharmaceutics Laboratory, Graduate Institute of Natural Products, Chang Gung University, 259 Wen-Hwa ${ }^{\text {st }}$ Road, Kweishan, Taoyuan 333, Taiwan. Fax: +886 32118236 .

E-mail address: fajy@mail.cgu.edu.tw (J.-Y. Fang).

1 Equal contribution. 
red wines. Resveratrol has attracted a lot of interest in 1992 because of a report demonstrating the cardioprotective activity discovered in red wine [4]. Resveratrol is a stilbenoid possessing two phenols linked by an ethylene bridge (Fig. 1). The chemical structure can be identified as two isomers: trans- and cis-resveratrol. The trans form is found in the plants, while the cis form is produced by isomerization of trans form and as a result of disintegration of resveratrol oligomers during the fermentation of grape skin in the presence of ultraviolet (UV) irradiation [5]. The trans form generally shows greater bioactivities than the cis structure.

Resveratrol can act as an antioxidant to modulate cellular functions. It scavenges hydroxyl radical, nitric oxide and superoxide anion [6]. The prevention and treatment of oxidative stress-related pathological conditions by resveratrol are largely investigated. Polyphenol is reported to prevent or treat cardiovascular disorder, cancer, diabetes

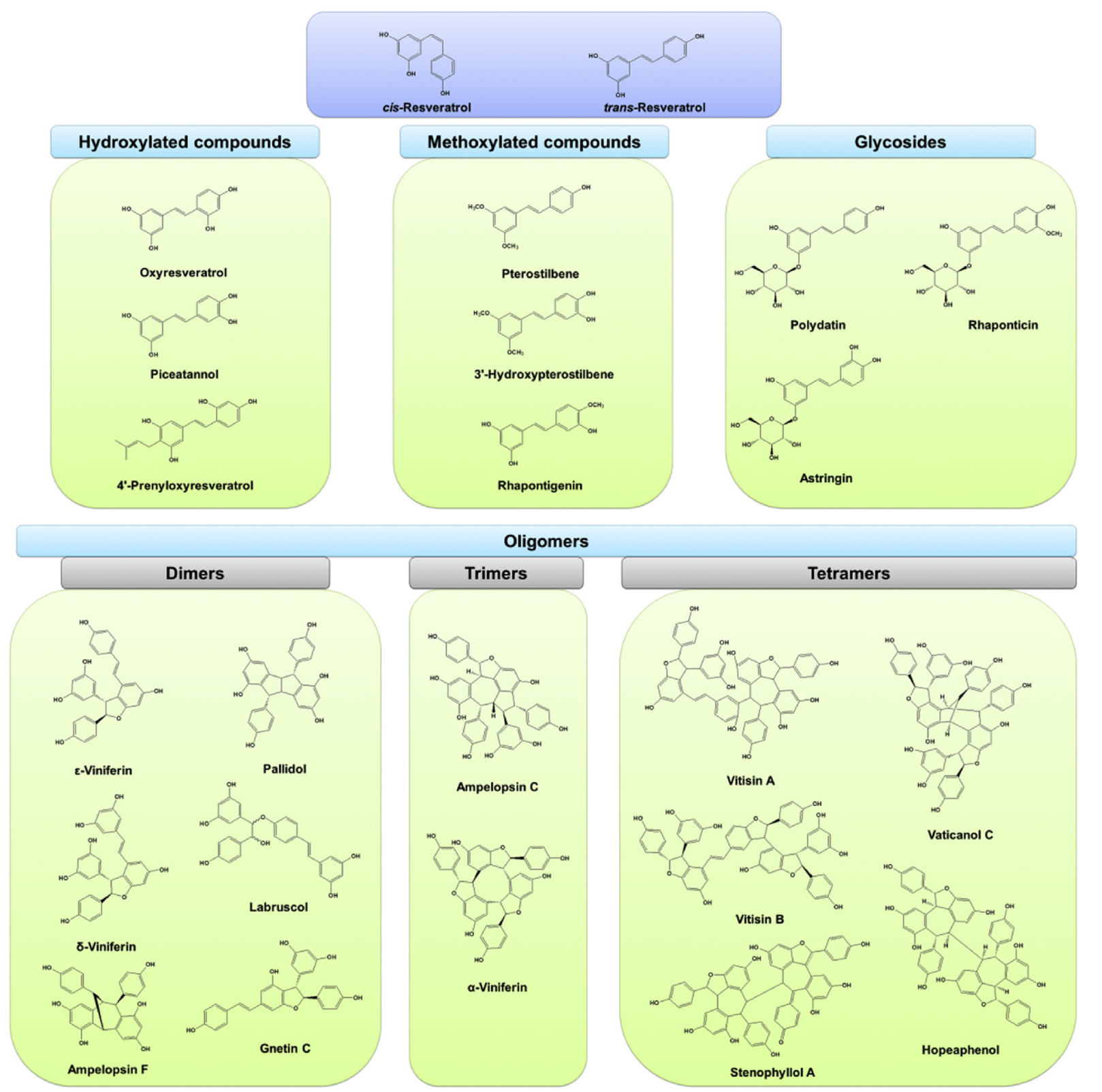

Fig. 1. The chemical structures of resveratrol and its naturally occurring derivatives discussed in this review. There are four groups of resveratrol derivatives, including hydroxylated compounds, methoxylated compounds, glycosides, and oligomers. The major oligomers with bioactivities on skin are dimmers, trimers, and tetramers. 
mellitus, microbial infection, aging, and inflammation [7]. Many resveratrol derivatives have been found in natural resources. These derivatives exhibit stilbene skeleton with various substituting moieties. There are four groups of resveratrol derivatives, including hydroxylated compounds, methoxylated compounds, glycosides and oligomers. The resveratrol derivatives also demonstrate biological activities covering wide diversities, such as anticancer, anti-aging, anti-inflammatory and antibacterial effects $[8,9]$. The predominant problem of resveratrol and its analogs associated with its applicability on disease treatment is the low oral bioavailability, as it gets metabolized via phase II enzymes [10]. In addition to the low bioavailability, resveratrol has very short half-life (8-14 $\mathrm{min})$ and undergoes extensive metabolism in the circulation [11]. Some strategies are employed to overcome the issues related with the low bioavailability. Among these strategies, skin delivery is a useful alternative of oral delivery for treating dermatological diseases. Resveratrol is reported to be readily absorbed through skin [12]. Additionally, the possible skin irritation caused by topical resveratrol is also reported to be low $[13,14]$.

Another approach for increasing the applicability of resveratrol-based therapy is to implement the use of nanomedicine [15]. Because of the low aqueous solubility and instability of resveratrol and its derivatives, nanoencapsulation is verified to be an efficient way to increase its solubility, bioavailability and other biological functions. The incorporation of resveratrol in nanocarriers will help to achieve the aim of enhanced stability, controlled release and tissue or organ targeting and therefore causes less side effects [16]. To increase the skin absorption of resveratrol, some nanoformulations such as liposomes, niosomes, solid lipid nanoparticles (SLNs), nanostructured lipid carriers (NLCs), nanoemulsions, polymeric nanoparticles, and dendrimers are utilized to promote the possible application of topical resveratrol (Fig. 2). Liposomes and niosomes can be classified as the nanovesicles with bilayers and aqueous cores. SLNs, NLCs, and nanoemulsions are the lipid-based nanocarriers with lipids in the cores. Polymer-based nanocarriers include poly(lactic-co-glycolic acid) (PLGA), polylactic acid (PLA), and dendrimers, which are commonly used in biomedical investigation due to their safety and tunable size. In the past few decades a great advancement in the investigation of resveratrol and its derivatives has demonstrated that it holds significant promise for skin use. In this review, we highlight the cutaneous application of resveratrol and its naturally occurring derivatives for treating skin disorders. We mainly focus on the reports of skin diseases treated by these stilbenoids using different evaluation platforms, including in vitro, ex vivo and in vivo examinations. The promising perspective associated with this emerging application is also discussed in the present study. The development of nanocarriers for improving the skin absorption capability and therapeutic efficacy of topical resveratrol is also introduced in this review article.

\section{Chemical structure of resveratrol and its derivatives}

The chemical structure of resveratrol consists of two phenolic rings which are bonded together by a double styrene bond. Resveratrol is equipped with different functional moieties including aromatic ring, hydroxyl group, and double bond. These groups offer a great potential to be conjugated with other moieties for structure modifications [17]. A large number of natural resveratrol derivatives are broadly investigated for their bioactivities. The structures of these compounds can be divided into hydroxylated derivatives, methoxylated derivatives, glycosides, and oligomers (Fig. 1). Some hydroxylated resveratrol derivatives are derived from natural products. These include oxyresveratrol, piceatannol, and prenyloxyresveratrol. The addition of hydroxyl group in resveratrol structure can increase the therapeutic versatility of the parent compound [18]. Oxyresveratrol can be derived from many plants, showing antioxidant and anti-inflammatory potential $[19,20]$. Oxyresveratrol has proved to reveal greater inhibition of tyrosine oxidation catalyzed by tyrosinase $\left(\mathrm{IC}_{50}=53 \mu \mathrm{M}\right)$ than that observed in the parent compound $\left(\mathrm{IC}_{50}>100 \mu \mathrm{M}\right)$ [21]. Another hydroxylated resveratrol derivative commonly studied is piceatannol, which possesses an additional hydroxyl group than resveratrol. Piceatannol is reported to have antioxidative, anticancer, immunomodulatory and anti-inflammatory effects [22].

The substitution of hydroxyl group by methoxyl group can increase the structural stability of resveratrol. The methoxyl resveratrol compounds demonstrate better bioavailability than the parent compound because of their higher lipophilicity [23]. The glucuronidation and sulfidation of methoxyl derivatives is less than the parent resveratrol during metabolism, confirming that methoxylation leads to stronger bioactivity response. Pterostilbene is a methoxylated resveratrol isolated from grapes, blueberries and some plant woods [24]. The anticancer, antilipidemic, and cardioprotective properties of pterostilbene are greater than that observed 


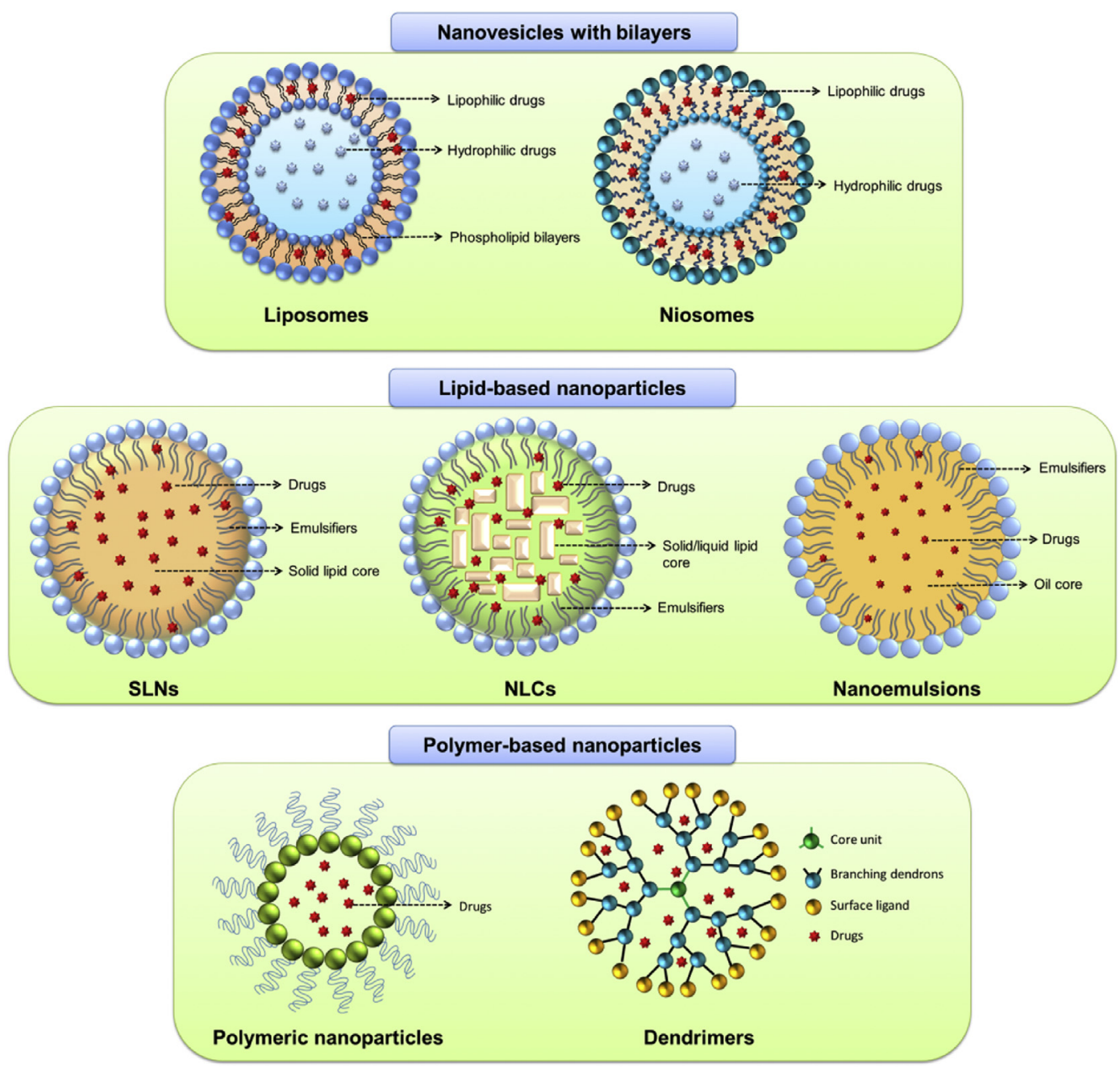

Fig. 2. The structures of nanocarriers used for cutaneous delivery of resveratrol and its naturally occurring derivatives. These nanosystems include liposomes, niosomes, solid lipid nanoparticles (SLNs), nanostructured lipid carriers (NLCs), nanoemulsions, polymeric nanoparticles, and dendrimers. The detailed description of the structures of these nanocarriers is shown in the text.

in resveratrol $[25,26]$. It is also reported that $3,4,5-$ trimethoxystilbene has more potent antioxidant and proapoptotic activities than that seen in resveratrol [18]. Another way to increase resveratrol bioavailability is through glycosylation. Glycosylation enhances resveratrol solubility in aqueous environment, leading to an improvement in its bioavailability [27]. The glycosylation process also prevents enzymatic oxidation which in turn preserves the biological activities and increases the stability. Polydatin, also known as piceid or resveratrol 3-O- $\beta$-D-glucopyranoside, is the most common resveratrol glycoside examined for bioactivities. This glycoside shows a structure in which a glucose is transferred to the C-3 hydroxyl moiety. Polydatin is abundant in red wine and grape juice. The concentration of polydatin in red wine is even higher than that of aglycone [28]. It is also detected in hop cones, beer and chocolates. Polydatin appears to be more efficacious than resveratrol in terms of antioxidant capacity because of the reaction linked with its radical form [29].

Resveratrol oligomers are biosynthesized via regioselective oxidative coupling of 2 to 8 monomers [30]. The oligomers can be formed through several self-mergers done by numerous distinct $\mathrm{C}-\mathrm{C}$ and $\mathrm{C}-\mathrm{O}$ binding [31]. At least 92 new resveratrol oligomers have been identified in plants in the last decade [32]. These oligomers have been reported to exert anticancer, antidiabetic, antibacterial and cardiovascular-protective effects [33,34]. The biological activities of resveratrol oligomers depend upon their molecular size and stereochemistry. Some studies [35,36] have demonstrated that the addition of increasing number of resveratrol units increase the biological potency and specificity. It is documented 
that the scavenging capacity and metal ion chelating ability of the oligomers are higher than that of the monomer by $20-$ and 1000 -fold [33]. The structures of resveratrol derivatives described in this review are illustrated in Fig. 1. Table 1 summarizes the physicochemical properties of these compounds as predicted by silico molecular modeling. Molecular volume, estimated lipophilicity (Alog $P$ ), hydrogen bond ( $\mathrm{H}$-bond) number and total surface polarity were also determined using Discovery Studio 4.1 (Accelrys).

\section{Skin disorders treated by resveratrol and its derivatives}

Skin is the largest and outermost organ, it provides the most accessible way to administer drugs and active ingredients. It is also a semipermeable barrier that protects the body from the external environment and it also prevents water loss. The skin of an average adult human covers a surface region of approximately $2 \mathrm{~m}^{2}$ and receives one-third of the blood circulation throughout the body. The largest organ of the human body, the skin, is composed of three histological layers: epidermis, dermis, and subcutaneous tissues. The skin delivery of drugs or active agents is often challenging due to the outer barrier of the skin. This barrier includes the stratum corneum (SC) and tight junction (TJ) [37]. SC, in particular, presents rigid resistance to the topical delivery of drugs. Successful skin delivery of drugs necessitates distinct characteristics regarding molecular size and physicochemical properties. The ideal physicochemical characteristics for facile skin absorption of permeates include low molecular weight $(<500 \mathrm{~g} / \mathrm{mol})$, moderate lipophilicity (partition coefficient $\log P=1-3$ ), adequate solubility in both water and oil, as well as have a low melting point [38]. Resveratrol and some of its derivatives fit in these criteria, resulting as the ideal candidate for topical administration to treat skin diseases and other abnormalities.

Skin disorder is a commonly found human illness, affecting about $70 \%$ of the population worldwide. It is the fourth leading cause of disability in the world [39]. For the management of skin diseases by drug therapy, topical administration renders an appealing approach as it provides various advantages including, direct nidus targeting, avoidance of systemic toxicity, and non-invasive application [40]. Recent application of resveratrol and its analogs in skin-related diseases includes therapies for skin

Table 1. Anti-skin cancer activity of resveratrol and its derivatives.

\begin{tabular}{|c|c|c|c|c|}
\hline Compound & Experimental model & Cell or animal type & $\begin{array}{l}\text { Outcomes offered by the } \\
\text { compound }\end{array}$ & Reference \\
\hline Resveratrol & In vitro SCC & Colo-16 cells & $\begin{array}{l}\text { Cell growth inhibition via } \\
\text { Wnt signaling }\end{array}$ & [68] \\
\hline Resveratrol & In vitro $\mathrm{SCC}$ & $\mathrm{Ca} 3 / 7$ cells & $\begin{array}{l}\text { Synergistic effect with ursolic } \\
\text { acid }\end{array}$ & [69] \\
\hline Resveratrol & In vivo phorbol ester induction & ICR mouse & $\begin{array}{l}\text { Tumor suppression by COX-2 } \\
\text { inhibition }\end{array}$ & [71] \\
\hline Resveratrol & In vivo phorbol ester induction & ICR mouse & $\begin{array}{l}\text { Tumor suppression via NF- } \kappa \mathrm{B} \\
\text { and AP-1 pathways }\end{array}$ & [72] \\
\hline Resveratrol & In vivo DMBA induction & Albino mouse & $\begin{array}{l}\text { Tumor suppression via PI3K } \\
\text { and protein kinase B } \\
\text { regulation }\end{array}$ & [73] \\
\hline Resveratrol & In vitro melanoma & B16-F10 and A375 cells & $\begin{array}{l}\text { Apoptosis via PI3K and } \\
\text { protein kinase B regulation }\end{array}$ & [75] \\
\hline Resveratrol & In vitro in vivo melanoma & DM738 and DM443 cells & $\begin{array}{l}\text { Synergistic effect with } \\
\text { temozolomide }\end{array}$ & [76] \\
\hline$\epsilon$-Viniferin and pallidol & In vitro melanoma & HT-144 and SKMEL-28 cells & $\begin{array}{l}\epsilon \text {-Viniferin displayed a } \\
\text { greater melanoma inhibition } \\
\text { than resveratrol and pallidol }\end{array}$ & [77] \\
\hline$\epsilon$-Viniferin and labruscol & In vitro melanoma & HT-144 and SKMEL-28 cells & $\begin{array}{l}\text { Melanoma inhibition via cell } \\
\text { cycle blocking in } S \text { phase }\end{array}$ & [78] \\
\hline Resveratrol in liposomes & In vitro melanoma & SKMEL-28 and Colo-38 cells & $\begin{array}{l}\text { Ultradeformable liposomes } \\
\text { enhanced cytotoxicity and } \\
\text { percutaneous permeation }\end{array}$ & [80] \\
\hline $\begin{array}{l}\text { Resveratrol in polymeric } \\
\text { nanoparticles }\end{array}$ & $\begin{array}{l}\text { In vitro melanoma and in } \\
\text { vivo phorbol ester induction }\end{array}$ & B16-F10 cells and mouse & $\begin{array}{l}\text { Nanoparticles enhanced } \\
\text { cytotoxicity and in vivo tumor } \\
\text { incidence }\end{array}$ & [81] \\
\hline
\end{tabular}

AP-1; activator protein-1; COX-2, cyclooxygenase-2; DMBA, 7,12-dimethylbenz[a]anthracene; NF- $\kappa \mathrm{B}$, nuclear factor- $\kappa \mathrm{B}$; PI3K, phosphatidylinositol-3-kinase; SCC, squamous cell carcinoma. 


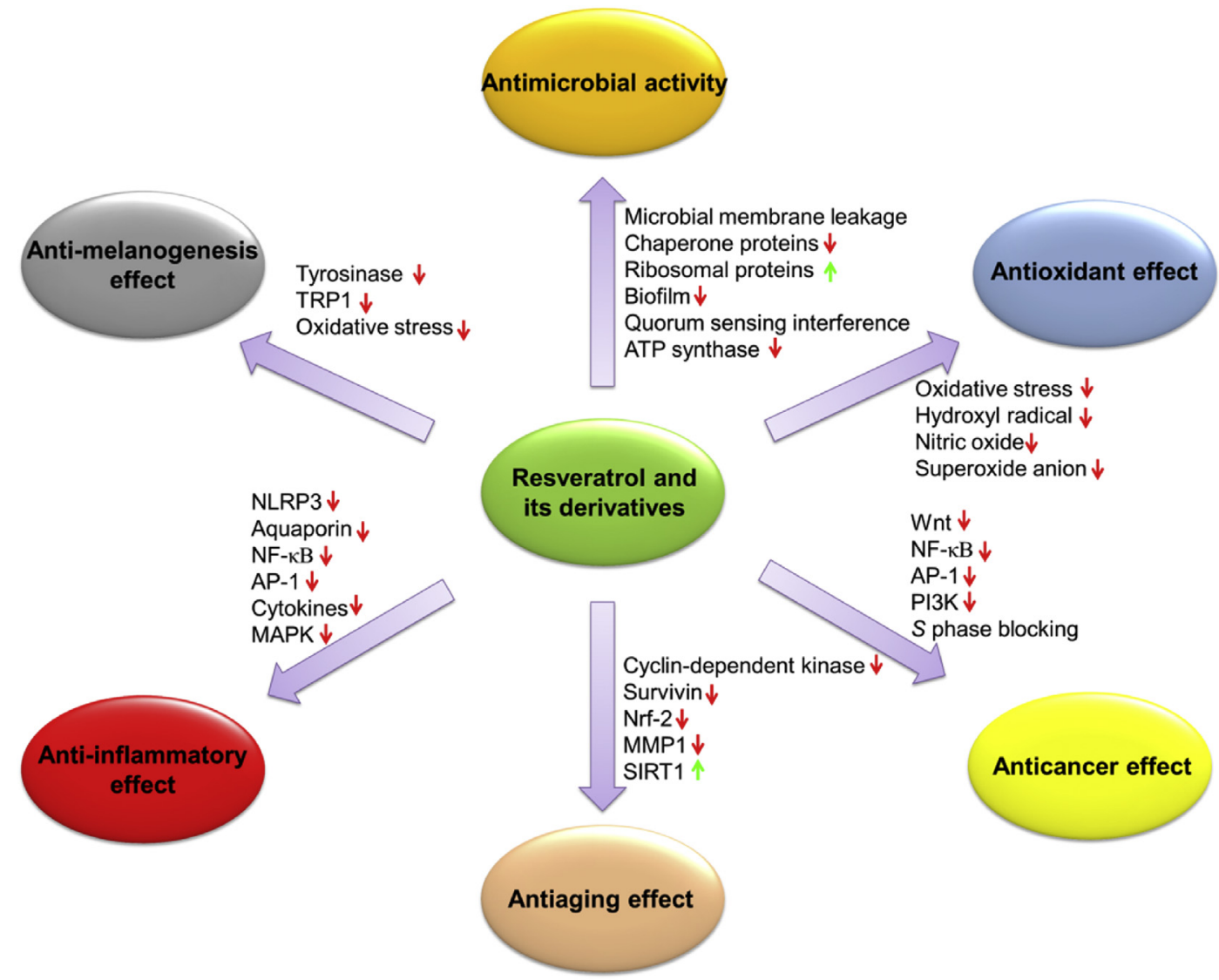

Fig. 3. The skin diseases that can be ameliorated by resveratrol and its naturally occurring derivatives in cell- or animal-based studies. The possible signaling pathways for the treatment of these skin disorders are summarized in this figure. Resveratrol and its analogs demonstrate antioxidant, anticancer, antiaging, anti-inflammatory, anti-melanogenesis, and antimicrobial impacts for skin application.

cancers, photoaging, intrinsic aging, cutaneous inflammation, melanogenesis, and microbial infection (Fig. 3). The possible mechanisms involving in the bioactivity of resveratrol and its analogs are also illustrated in this figure. The use of these active compounds can ameliorate the symptoms of the skin diseases. Some therapies based on resveratrol properties have been approved for clinical use or are under clinical trial for preventive or therapeutic use. In addition, some resveratrol or the derivatives are approved to manage various skin diseases in cellbased and animal studies. Some of these resveratrolrelated compounds are included in topical formulations for cosmetic purposes [41].

Skin cancer is the most common form of cancer, globally accounting for at least $40 \%$ of cancer cases [42]. There are three major types of cutaneous tumors, including basal cell carcinoma (BCC), squamous cell carcinoma (SCC) and melanoma. The first two can be classified as non-melanoma skin cancers (NMSC). Mohs micrographic surgery (Mohs surgery) is a technique used to remove the cancer with the least amount of surrounding tissue and the edges are checked immediately to see if any tumor is detected. For low-risk diseases, radiation therapy, topical chemotherapy and cryotherapy can provide adequate control of the disease [43]. The topical chemotherapy is also used for the prevention of tumor recurrence after surgical removal. Some polyphenolic compounds such as phenolic acids, flavonoids, stilbenes, and lignans have proved to be effective for mitigating the tumor growth of NMSC and melanoma [44]. These compounds act on several biomolecular pathways including, cell division cycle arrest, autophagy, and apoptosis. Cutaneous aging can be divided into photoaging and chronological aging. Photoaging is activated via the human skin damage attributable to repeated UV exposure from sunlight. Exposure to UV radiation from the sun is the main risk factor for causing skin cancer [45]. UV elicits both acute and chronic adverse effects on the skin. These include sunburn, photosensitivity, inflammation, immunosuppression, and photocarcinogenesis [46]. UV exposure of the skin creates reactive oxygen species (ROS), leading to the massive infiltration of immune cells such as neutrophils and macrophages 


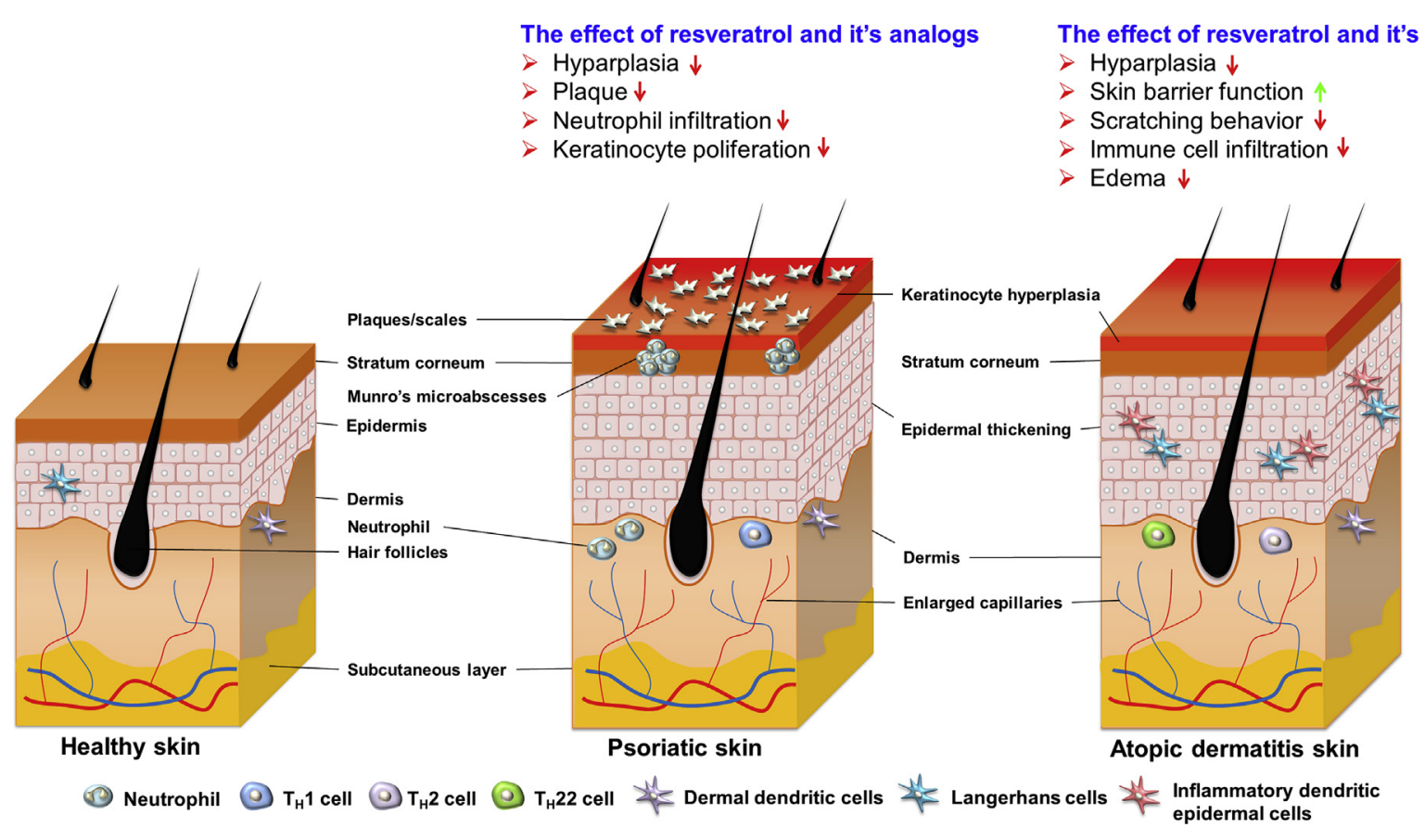

Fig. 4. The morphologies and features of psoriasis and atopic dermatitis skins. Typical histologic features of psoriasis includes epidermal hyperplasia with elongated rete ridges, a less discrete epidermal granular layer, parakeratosis, and leukocyte infiltration of the viable skin. Dermatitis is an inflammatory skin disease characterized by presence of erythema, edema, vesicles, and lichenification. The effects of resveratrol and its analogs on psoriasis and dermatitis for ameliorating the signs and symptoms are summarized in this figure.

in viable skin cells [47]. Due to its antioxidant property, resveratrol and its derivatives have the capability to ameliorate cutaneous photoaging.

Inflammatory skin diseases are the most common problem in dermatology. They can range from occasional rashes accompanied by skin itching and redness, to chronic conditions such as psoriasis, dermatitis, and rosacea. Both psoriasis and atopic dermatitis (AD) are autoimmune diseases affecting skin. Psoriasis, a chronic inflammatory disease of the skin, affects approximately 125 million people globally [48]. Clinically, psoriasis is characterized by red plaques with silver or white multilayered scales with a thickened acanthotic epidermis in patients who are markedly demarcated from adjacent nonlesional skin (Fig. 4) and its lesions often occur at sites of epidermal trauma, such as the elbows and knees, the back, and the trunk, but it can appear anywhere on the body, which severely impairs patients' quality of life [49]. Typical histologic features of psoriasis includes epidermal hyperplasia with elongated rete ridges, a less discrete epidermal granular layer, parakeratosis, and leukocyte infiltration of the viable skin. More than $80 \%$ of patients show a mild-to-moderate level of severity [50], which can be controlled by topical therapy. However, conventional topical-application treatment is usually time-consuming with incomplete lesion resolution and some adverse effects. The development of new topically applied agents is definitely needed, especially the ones discovered from natural resources [51]. Some natural compounds are useful for treating psoriasis because of their antioxidant, anti-inflammatory and apoptotic activities [52].

$\mathrm{AD}$ is an inflammatory skin disease characterized by presence of erythema, edema, vesicles, and lichenification (Fig. 4). The pathogenesis of AD involves dysregulation in the inflammatory process and a change in response to antigens. The prevalence of $\mathrm{AD}$ has increased 3-fold over the past 30 years because of environmental risks [53]. It is a common skin disorder affecting $10-25 \%$ of children and $2-10 \%$ of adults [54]. The anti-AD drugs such as coal tar, doxepin, calcineurin inhibitors and steroids are reported to cause skin itching and stinging sensation [55]. The excessive use of topically applied calcineurin inhibitors may elicit systemic absorption, therefore, causing toxicity and increasing the malignancy risk. Corticosteroids are usually accompanied by side effects such as skin thinning, striae, corticophobia and also demonstrate insufficient clinical response [56]. The development of new agents for $\mathrm{AD}$ treatment is urgently needed to minimize these side effects and enhance the efficacy. Several investigations assessing anti-AD therapy based on natural sources have revealed some potential activities in this area [57]. There are 
two important features associated with $\mathrm{AD}$ that make it difficult to treat. Firstly, it compromises the skin barrier and secondly, increases the risk of cutaneous infection. As the integrity of barrier is reduced this leads to Staphylococcus aureus invasion and exacerbates eczema [58]. More than $90 \%$ of AD patients are colonized with $S$. aureus [59]. The bacterial population increases in the skin involving lesions of $\mathrm{AD}$ and chronic wounds. Hence it plays a critical role in infection-induced inflammation and cutaneous disease progression [60]. Polyphenols including resveratrol-related compounds can be used to treat cutaneous and subcutaneous infections caused by bacteria and fungi $[61,62]$.

Resveratrol and its derivatives are also investigated for skin hyperpigmentation treatment. These compounds can act as skin lightening agents to improve skin aesthetics. Hyperpigmentation occurs when the skin releases more melanin content. Melanin is the pigment which gives skin its color. This can make spots or patches of skin appear darker than surrounding areas. Hyperpigmentation can occur after an injury or due to skin inflammation caused during cuts, burns, acne, and lupus. Excessive sun exposure and melasma can also cause hyperpigmentation [63]. Tyrosinase is regarded as a key enzyme implicated in the metabolism of melanin in melanocytes and its inhibitors have become increasingly important in medicinal and cosmetic products in relation to hyperpigmentation. Resveratrol has been already proved as a tyrosinase inhibitor which can reduce the cutaneous pigmentation [64].

\section{Resveratrol and its derivatives as the active agents for skin-related disease therapy}

The following review describes the different therapeutic and cosmetic approaches of resveratrol and its analogs on skin. These include the cell-based study, animal-based study and clinical human trial. The pharmacodynamics outcome of these compounds are the main evaluation platform used to define the preventive or therapeutic effects in our present description.

\subsection{Skin cancers}

Chemotherapy or chemoprevention by natural compounds is appreciated as a new strategy in the management of carcinomas including skin cancers. The anticancer ability of resveratrol is verified by in vitro and in vivo evaluations. The tumor inhibition by resveratrol involves its antioxidant, anti-inflammatory, antiproliferative and pro-apoptotic activities
[65]. Resveratrol can suppress carcinogenesis at different stages, including initiation, promotion, and progression [66]. SCC is a common form of skin cancer which develops in the squamous cells that make up the middle and outer layers of the skin. It is usually found in areas of the skin damaged by excessive UV exposure from the sun. Surgery is the first choice for treating SCC, whereas the adjuvant therapy by chemotherapy can improve the survival rate and life's quality. Wnt/ $\beta$-catenin signaling is activated in the process of development of SCC [67]. The effect of resveratrol on cell growth and how it impacts Wnt signaling of SCC Colo-16 cells was investigated by Liu et al. [68]. The concentration of resveratrol that inhibited $50 \%$ of SCC cell growth $\left(\mathrm{IC}_{50}\right)$ was $114 \mu \mathrm{M}$. It was reported that Wnt2 expression was downregulated accompanied by increased expression of Wnt inhibitor Axin2. It was suggested that the inactivation of Wnt pathway was the main target of resveratrol associated with restraining SCC growth. Resveratrol can also be used as an enhancer to synergize anti-SCC activity of ursolic acid [69]. Ursolic acid is approved as an efficient natural compound to induce death of skin cancer cell lines via AMP-activated protein kinase [70]. Resveratrol if used at a concentration of $25 \mu \mathrm{M}$ enhances antiproliferative effects of ursolic acid in the $\mathrm{Ca} 3 / 7$ cell lines in a dose-dependent fashion. The $\mathrm{IC}_{50}$ of ursolic acid could be reduced by 2.3 -fold after the co-treatment with resveratrol at $100 \mu \mathrm{M}$.

An earlier study [71] has investigated the impact of resveratrol on phorbol ester-induced skin cancer in mouse. Phorbol ester can be used as an activator to induce NMSC-like model. Aberrant cyclooxygenase (COX)-2 expression is an indicator of tumor promotion. It was seen that the topical delivery of resveratrol at $1 \mu \mathrm{mol}, 30 \mathrm{mins}$ prior to phorbol ester treatment decreased COX-2 level in mouse skin. Phorbol ester intervention resulted in the induction of IКB kinase activity in skin, which could be abolished by topical application of resveratrol. Besides I $\kappa \mathrm{B}$ kinase, the COX-2 upregulation in the skin cancer is activated via nuclear factor (NF)$\kappa \mathrm{B}$ that is regulated by mitogen-activated protein kinase (MAPK). Kundu et al. [72] found that topical resveratrol inhibited $\mathrm{NF}-\kappa \mathrm{B}$ and activator protein (AP)-1 activities in phorbol ester-induced skin tumor. Both signal pathways could be the prime targets of resveratrol to inhibit skin cancer. In a study, the chemopreventive effect of topical resveratrol was also examined in the 7,12-dimethylbenz[a]anthracene (DMBA)-induced mouse skin tumor [73]. Topical resveratrol treatment was given to mice 1 hour before initiating DMBA treatment for 28 weeks. The induction of first tumor was 
detected after 52 days with regard to the vehicle control. The onset could be delayed by 73 to 79 days after receiving resveratrol at a dosage of 25 and 50 $\mu \mathrm{M}$ respectively. Resveratrol administration at 25 $\mu \mathrm{M}$ and $50 \mu \mathrm{M}$ led to a reduction in tumor volume by $51 \%$ and $65 \%$ respectively. This inhibition by resveratrol was confirmed due to the involvement of phosphatidylinositol-3-kinase (PI3K) and protein kinase B.

Melanoma is a type of skin cancer characterized by an aggressive pathogenesis and poor response to therapy. Cutaneous melanoma originates from genetically altered melanocytes in the epidermal basal layer. It is reported that some polyphenols such as curcumin, quercetin, coumarin and resveratrol display antioxidant, anti-inflammatory and antiproliferative efficacies to inhibit melanoma [74]. In a cell-based assay [75], murine melanoma (B16-F10) and human melanoma (A375) cell lines were used as the models to examine the effect of resveratrol on melanoma. Resveratrol at a dose of $100 \mu \mathrm{M}$ increases apoptosis of both cell lines by 46 -fold as compared to that of the control. The autophagy-related proteins including Beclin 1 and microtubule-associated protein 1A/1B-light chain 3 (LC3)-II/I were upregulated after resveratrol treatment. Phosphorylated PI3K and protein kinase B were also reduced by this compound. Since autophagy is vital for the growth of malignancies, the results have led to the development of targeted melanoma treatment by resveratrol. Osmond et al. [76] conducted in vitro and in vivo cytotoxicity of resveratrol against melanoma cell lines, DM738 and DM443. Resveratrol treatment at doses of $<50 \mu \mathrm{M}$ manifested a dose-dependent cytotoxicity, whereas the doses between $50 \mu \mathrm{M}$ and $100 \mu \mathrm{M}$ showed no additional effect. It is demonstrated that resveratrol also significantly enhances cytotoxicity of temozolomide, an antimelanoma drug. The mouse with subcutaneous DM738 xenograft was treated with resveratrol $(90$ $\mathrm{mg} / \mathrm{kg}) 2$ days prior to initiating temozolomide treatment. The results showed that cyclin B and D1 were reduced by resveratrol after a 2-day treatment.

$\epsilon$-Viniferin and pallidol are the dimers of resveratrol. Nivelle et al. [77] found that pallidol revealed a comparable inhibition of the growth of melanoma cell lines, namely HT-144 and SKMEL-28 which are similar to that observed with resveratrol treatment. The dehydrodimer $\epsilon$-viniferin showed considerably higher inhibition than resveratrol and pallidol. The $\mathrm{IC}_{50}$ of $\epsilon$-viniferin against HT-144 and SKMEL-28 was $18 \mu \mathrm{M}$ and $16 \mu \mathrm{M}$ respectively which was lower than that of resveratrol and pallidol $(>100 \mu \mathrm{M})$. The mechanisms behind anti-melanoma activity of $\epsilon-$ viniferin were further explored in the cell-based study [78]. Another dimer, labruscol, was also employed for comparison. The $\mathrm{IC}_{50}$ of $\epsilon$-viniferin and labruscol against HT-144 metastatic cells in the presence of fetal bovine serum was $65 \mu \mathrm{M}$ and 54 $\mu \mathrm{M}$ respectively. Labruscol induced more necrosis $(40 \%)$ in HT-144 metastatic cells as compared to $\epsilon-$ viniferin $(25 \%)$ and resveratrol $(18 \%)$. All these compounds blocked cell cycle of melanoma during $S$ phase by modulating cell cycle regulators such as cyclin A, E, and D1. It was reported that this effect demonstrated no cytotoxicity on normal dermal fibroblasts.

Nanocarriers are used to load resveratrol for enhanced skin delivery to treat skin cancers. Ultradeformable liposomes are forms of nano-sized vesicles consisting of phospholipids and edge activator, capable of increasing the flexibility of liposomal bilayers to squeeze into SC [79]. Cosco et al. [80] prepared the ultradeformable liposomes with a mean diameter of $<120 \mathrm{~nm}$. The co-entrapment of resveratrol and 5-fluorouracil in ultradeformable liposomes increases the cytotoxicity more against SKMEL-28 and Colo-38 cells than that observed with free compounds and single compounds in liposomes. This nanoformulation arrested cell proliferation in G1/S phase. The skin permeation of resveratrol and 5-fluorouracil across human epidermis was increased by 8.3- and 6.2-fold respectively after liposomal encapsulation. Bano et al. [81] developed polymeric nanoparticles made with poly (N-isopropylacrylamide) (PNIPAAM)polyethylene glycol (PEG) encapsulated with resveratrol for evaluating inhibitory efficacy on skin cancer. The nanoparticle size was around $100 \mathrm{~nm}$ with a high resveratrol encapsulation percentage of $>80 \%$. The loading of resveratrol into nanoparticles decreased B16-F10 cell viability from $60 \%$ to $40 \%$. In the promotion phase of in vivo skin cancer induced by phorbol ester, a significant reduction was found in tumor incidence and tumor burden in mice which were pretreated with nanoparticles. The percentage of mice with tumors was $82 \%$ after intervention. This percentage was reduced to $19 \%$ and $6 \%$ by treatment with free resveratrol and resveratrol-loaded nanoparticles respectively. The nanocarriers upregulated Bax expression, leading to the apoptosis of the phorbol ester-induced tumor. The anti-skin cancer activity of resveratrol and its analogs is summarized in Table 1. 


\subsection{Extrinsic aging and photoaging}

Skin aging is divided into intrinsic and extrinsic modes. Extrinsic and intrinsic aging is caused by environmental and genetic factors respectively [82]. Extrinsic skin aging can be induced by UV exposure, smoking, air pollution and poor nutrition. Intrinsic aging, also named as chronological aging, is a slow biological process characterized by fine wrinkling, fragility, reduced elasticity, loss of skin tone and mottled pigmentation [83]. Polyphenols can be used as antioxidants to treat skin aging because of the capability to donate hydrogen atoms which helps to neutralize free radical species produced during oxidative stress [84]. The free radicals are formed under the influence of UV exposure, toxins, and smoking. Sirtuin is an enzyme that is associated with regeneration, vitality, and resistance of the mammalian cells. The activity of sirtuin decreases with the increase in age [85]. Resveratrol can slow the process of skin aging due its role as a sirtuin activator and free radical scavenger [86]. Topical delivery is beneficial to replenish resveratrol in skin, resulting in the efficient prevention of skin aging and damage by oxidative stress. Alonso et al. [87] compared the antioxidative effect of five polyphenols on skin after their topical application. The polyphenols included epicatechin, quercetin, rutin, trolox and resveratrol. Polyphenols were extracted from the pig skin treated by topically applied polyphenols using Franz cell assembly. 1,1-Diphenyl-2picrylhydrazyl (DPPH) assay was used to determine antioxidant activity. Among the polyphenols, rutin and resveratrol were observed to be more favorable for inhibiting DPPH. Resveratrol deposition in epidermis was $2.02 \mathrm{nmol} / \mathrm{cm}^{2}$, which was much higher than rutin $\left(0.66 \mathrm{nmol} / \mathrm{cm}^{2}\right)$, indicating a satisfactory percutaneous absorption of resveratrol. The skin absorption of resveratrol was further investigated in the in vivo human model [88]. Six volunteers who participated in this study received topically applied resveratrol $\left(500 \mu \mathrm{g} / \mathrm{cm}^{2}\right)$ on the forearm surface. The results showed that the major amount $(77 \%)$ of permeated compound was located in the upper SC layer. The DPPH inhibition caused by resveratrol which was deposited in SC layer was $28 \%$.

The UV radiation is the main etiological factor which elicits premature skin aging. It is also the major cause behind skin cancer [89]. To prove the photoprotective properties of resveratrol on skin, Park and Lee [90] treated UVB-irradiated HaCaT keratinocytes by resveratrol. It was observed that pretreatment by resveratrol at the doses of $5-100$ $\mu \mathrm{M}$ markedly increased keratinocyte survival in the presence of UVB. The ROS production was also attenuated by resveratrol pretreatment. The activation of caspase- 3 and -8 was inhibited in resveratroltreated $(100 \mu \mathrm{M}) \mathrm{HaCaT}$ keratinocytes by one and a half times. In an in vivo hairless mouse model, topical resveratrol $(10 \mu \mathrm{mol}$ per mouse) was applied on the dorsal skin exposed to UVB at $180 \mathrm{~mJ} / \mathrm{cm}^{2}$ [91]. The findings demonstrated that UVB increased skin thickness (2-fold), cyclin-dependent kinase-2 (cdk) (3-fold), cdk-4 (3 fold), cdk-6 (4-fold), cyclin D1 (2-fold), and cyclin D2 (2-fold) in epidermis. Resveratrol could downregulate these cell cycle regulatory proteins, suggesting the antiproliferative activity of resveratrol on photoaged skin. Aziz et al. [92] further verified the primary role of survivin, the inhibitor of apoptosis protein family, on resveratrolmediated protection from UVB in hairless mouse model. It was seen that UVB light significantly upregulated survivin expression in skin. In the UVB-exposed mouse topical pretreatment of resveratrol, at a dose of $10 \mu \mathrm{mol}$, resulted in the inhibition of survivin protein by two-third.

Pterostilbene is a methoxylated resveratrol with potent antioxidative activity. The inhibitory effect of pterostilbene on UVB-induced photodamage in keratinovytes was investigated in a study [93]. $\mathrm{HaCaT}$ keratinocytes were pretreated with pterostilbene at a dose of 5 or $10 \mu \mathrm{M}$ prior to UVB irradiation $\left(300 \mathrm{~mJ} / \mathrm{cm}^{2}\right)$. Pterostilbene attenuated UVB-evoked cell death and ROS generation. The nuclear translocation of nuclear factor erythroid 2related factor 2 (Nrf2) and the Nrf2-dependent antioxidant enzymes were increased after pterostilbene intervention. Nrf2 pathway exerts a critical role in promoting defense against oxidative stress [94]. SKH-1 hairless mouse was used as the in vivo model to test whether pterostilbene was effective for treating UVB-induced skin disruption [95]. Topical application of pterostilbene demonstrated a dramatic decrease in UVB-evoked skin tumorgenesis (90\% tumor-free animals) after 40 weeks, whereas resveratrol showed no such effect $(0 \%)$. The results highlighted that pterostilbene could suppress oxidative damage caused by UVB but resveratrol is unable to do so. Pterostilbene maintained a high level $(150 \mu \mathrm{mol} / \mathrm{kg})$ in the skin after a 6-h topical administration at a dose of $1 \mu \mathrm{mol} / \mathrm{cm}^{2}$. Polydatin is a resveratrol glycoside displaying strong antioxidative activities. He et al. [96] demonstrated that polydatin protects the skin from UVB-induced damage as seen in both in vitro and in vivo experiments. There was no cytotoxicity noticed in HaCaT cells, treated with polydatin at a dose up to $100 \mu \mathrm{g} /$ $\mathrm{ml}$. UVB exposure at $30 \mathrm{~mJ} / \mathrm{cm}^{2}$ led to $43 \% \mathrm{HaCaT}$ cell death compared to that of the control. Polydatin 
reduced the cell death and ROS production elicited by UVB in a dose-dependent manner $(0-80 \mu \mathrm{g} / \mathrm{ml})$. The findings of the study confirmed that UVB irradiation $\left(360 \mathrm{~mJ} / \mathrm{cm}^{2}\right)$ on nude mouse skin resulted in desquamation and erythema and topical delivery of polydatin $(10 \mathrm{mg} / \mathrm{ml})$ could reverse these symptoms. The results showed that the epidermal thickness is increased by UVB $(87 \mu \mathrm{m})$ and decreased by using polydatin $(38 \mu \mathrm{m})$. In addition to the role of antioxidant, polydatin acted as a sunscreen to retard UVBinduced photoaging. Matrix metalloproteinase (MMP)-1 plays a major role and is involved at multiple stages of skin photoaging [97]. Some resveratrol oligomers derived from Vatica albiramis have proved to exert the ability to arrest MMP-1 in dermal fibroblasts [36]. IL-1 $\beta$ initiated MMP-1 production from human foreskin fibroblasts. Three oligomers including (-)-hopeaphenol, vaticanol C and stenophyllol $\mathrm{C}$ exhibited significant inhibition on MMP-1. These oligomers were tetramers. Resveratrol dimers had negligible or very less activity associated with the suppression of MMP-1 release.

Like the ultradeformable liposomes, transfersomes and ethosomes are elastic nanovesicles used for improving skin delivery of the bioactive agents [98]. Transfersomes consist of surfactants such as polysorbate 80 , sodium cholate, and sodium deoxycholate which helps to increase the phospholipid bilayer flexibility. Nanovesicles are composed of phospholipids, water and ethanol, they form ethosomes which interacts with SC layer. Scognamiglio et al. [99] prepared transfersomes and ethosomes for loading resveratrol. The prepared nanovesicles showed mean diameters between 83 and $116 \mathrm{~nm}$ with a high resveratrol encapsulation of $>70 \% . \mathrm{H}_{2} \mathrm{O}_{2}$ treatment on $\mathrm{HaCaT}$ cells increases ROS production. This elevation was inhibited by polysorbate 80 -incorporated $(62 \%)$, sodium cholate-incorporated $(62 \%)$, and sodium deoxycholate-incorporated $(48 \%)$ transfersomes loaded with $2 \mu \mathrm{g} / \mathrm{ml}$ resveratrol. It was seen that the ROS reduction by ethosomes was only $23 \%$. The in vitro study involving pig ear skin permeation demonstrated that only ethosomes could increase resveratrol delivery across the skin. Wu et al. [100] also prepared resveratrol-loaded transfersomes which were incorporated with polysorbate 20, polysorbate 80 , or Plantacare 1200 UP. The vesicle size ranged between 43 and $81 \mathrm{~nm}$. The antioxidant activity as determined by DPPH and 2,2'-azinobis(3-ethylbenz thiazoline-6-sulphonic acid) (ABTS) assays revealed a comparable inhibition associated with free resveratrol. However, the in vitro permeation study showed that polysorbate 20 - incorporated transfersomes enhanced resveratrol delivery by $28 \%$. Lipid nanocarriers, such as SLNs, NLCs, and nanoemulsions, appear to be suitable as drug-carrier systems due to their very low cytotoxicity as compared to polymeric nanoparticles [101]. The predominant difference among SLNs, NLCs and nanoemulsions is related to the composition of the inner core. SLNs are particles that are made from crystalline solid lipids, whereas NLCs are composed of a solid lipid matrix with a certain content of liquid lipid; they are a more advanced generation of SLNs. Nanoemulsions are nanocarriers with neat liquid oil in the inner phase. Gokce et al. [102] in a study entrapped resveratrol into SLNs and NLCs to examine its antioxidative effect and skin absorption capacity. The average size of SLNs and NLCs was 287 and $111 \mathrm{~nm}$ respectively. The smaller size of NLCs with a reduced negative surface charge favored endocytosis into dermal fibroblasts, resulting in less ROS production than that observed in SLNs. In the in vitro study, rat skin absorption indicated a higher resveratrol deposition in epidermis by application of NLCs $\left(1.99 \mu \mathrm{g} / \mathrm{cm}^{2}\right)$ than that seen with SLNs $\left(1.55 \mu \mathrm{g} / \mathrm{cm}^{2}\right)$.

\subsection{Intrinsic aging and cosmetic use}

Intrinsic skin aging is caused by senescence and other intrinsic factors which leads to skin atrophy. Presence of wrinkles, collagen loss, decreased hydration and skin thinning are the symptoms commonly observed in the aged skin. Oxidative stress is strongly associated with skin aging because of the progressive accumulation of ROS in skin, as age increases [103]. Natural antioxidants are used in the production of pharmaceutical or cosmetic formulations with the aim of delaying the skin aging process and ameliorating skin aesthetics [104]. Gnetum gnemon (melinjo) is an arboreal dioecious plant extensively cultivated in South Asia. The seeds of this plant are abundant in resveratrol and its glycosides and dimers [105]. Watanabe et al. [106] evaluated the protective effects of melinjo seed extract on age-related skin pathology as demonstrated in mouse. Superoxide dismutase 1 (SOD1) is an enzyme that is essential for the maintenance of skin homeostasis. The seed extract or resveratrol was orally administered to $\mathrm{Sod}^{-1-}$ mice daily for 12 weeks. The treatment that was conducted by using extract or resveratrol reversed skin thinning associated with increased oxidative damage in $\mathrm{Sod}^{-1-}$ mice. The gene expression of Sirt1 in skin was upregulated by the usage of extract and resveratrol. The in vitro 
experiment also verified that resveratrol could elevate the viability of $\mathrm{Sod}^{-1-}$ fibroblasts.

Resveratrol and its derivatives showed beneficial outcomes when added into the skincare products. Some clinical trials are being conducted to test the improvement associated with skin aging by resveratrol-related products. A clinical study was carried out in 20 subjects over a period of 6 weeks, receiving topically applied resveratrol $(0.007 \%)$-containing oilin-water cold cream [107]. The skin hydration was assessed in both the groups (with or without resveratrol intervention). The results showed that the hydration level was increased up to 2-fold as compared to the vehicle control after resveratrol was applied for 4 weeks. Resveratrol permeated into the epidermis to supplement the lipids and protective layers, increasing the moisturizing and tightening characteristics. Another clinical study was performed among 50 volunteers who received dietary supplement of grape fruit extract, rich in resveratrol and procyanidins for estimating skin condition [108]. It is important to note that $133 \mathrm{mg}$ of extract contains $8 \mathrm{mg}$ of resveratrol and $14.63 \mathrm{mg}$ of procyanidins. The study results showed that skin moisturization and elasticity had been improved by the dietary supplementation as measured by bioengineering techniques, while the skin roughness and wrinkling also reduced. The antioxidant capacity detected by oxyadsorbent assay showed a significant improvement in the treated group than that of the placebo group.

Pterostilbene $(0.4 \%)$ loaded in cream was topically applied for 8 weeks on 38 volunteers in an open-label, single-arm study [109]. The skin hydration, brightness, elasticity were examined by bioengineering methods to achieve quantifiable results. The findings showed that pterostilbene cream successfully reduced wrinkles and fine lines. The skin moisturization and elasticity were also improved with no demonstration of adverse effects. A significant improvement in skin fairness was observed according to the subjective assessment conducted by dermatologists. Lipid-based nanoparticles such as SLNs, NLCs, and nanoemulsions have proved to exert occlusive effect, enhancing skin hydration [110]. Montenegro et al. [111] evaluated the capability of cutaneous hydration as increased by SLNs, NLCs and nanoemulsions, encapsulated with $1 \%$ resveratrol. The nanoparticle diameters of SLNs, NLCs and nanoemulsions were 46,26 , and $27 \mathrm{~nm}$ respectively. The prepared nanocarriers were incorporated in the hydrogels to be applied on the forearm of 12 healthy subjects for one week. An increase in skin hydration was detected for all nanocarriers with a tendency of SLNs $>$ NLCs $>$ nanoemulsions. This could be due to the higher degree of crystallinity seen in SLNs than that observed in the other nanosystems which led to a better occlusion effect. The inhibitory effect of resveratrol and its natural derivatives on extrinsic and intrinsic aging is listed in Table 2.

\subsection{Skin inflammation and autoimmune diseases}

Skin appears to act not only as the sensor during stressful conditions (toxin, pathogen, UV), but also plays a major role in conducting an orchestrated recruitment and promoting function of the immune cells which are involved in inflammation. Inflammation is central to the pathogenesis of some skinrelated diseases such as eczema, psoriasis, dermatitis, vitiligo, and lupus erythematosus [112]. Resveratrol is a molecule that can mitigate skin inflammation, including autoimmune diseases [113]. Resveratrol targets some of the molecules such as COX-2, 5-lipoxygenase, and protein kinase B and is associated with the ability to suppress COX-1 or COX-2 activity [114]. Resveratrol was able to restrain keratinocyte proliferation through the inhibition of aquaporin 3, a vital cell survival regulator [115]. This inhibition occurred due to SIRT1 activation, resulting in the increased activation of aryl hydrocarbon receptor nuclear translocator (ARNT). This led to extracellular signal-regulated kinase (ERK) dephosphorylation, preventing aquaporin 3 activation. This inhibition process caused by resveratrol implicated that it can be used to treat hyperplastic skin disorders such as psoriasis.

Kjaer et al. [116] examined the impact of orally administered resveratrol on imiquimod-induced psoriasiform skin in mouse. Resveratrol was given at a dose of $400 \mathrm{mg} / \mathrm{kg}$ per day. Skinfold thickness increased from 0.55 to $0.82 \mathrm{~mm}$ after imiquimod intervention. This is a typical sign of psoriasis development. It was observed that oral resveratrol reduced the thickness to $0.71 \mathrm{~nm}$. The results presented that the severity of scaling and erythema evoked by imiquimod could be alleviated by resveratrol. In addition, the gene expression of IL17A, IL-19, and IL-23p19 in skin which was increased by imiquimod was downregulated after resveratrol treatment. Besides inducing skin cancer, 12-O-tetradecanoylphorbol-13-acetate (TPA) can act as a stimulator eliciting psoriasis-like lesion in mouse because of its capability to cause hyperplasia and evoke inflammatory cell infiltration [117]. Murakami et al. [118] used TPA to induce acute skin inflammation in the ear skin of the mouse for examining whether resveratrol could reduce the inflammatory response. The skin thickness which was increased by TPA $(0.30 \mathrm{~mm})$ could be 
Table 2. Extrinsic and intrinsic aging treated by resveratrol and its derivatives.

\begin{tabular}{|c|c|c|c|c|}
\hline Compound & Experimental model & Cell or animal type & Outcomes offered by the compound & Reference \\
\hline Resveratrol & In vitro skin absorption & Pig & $\begin{array}{l}\text { Resveratrol showed a satisfied skin } \\
\text { absorption to exert antioxidative } \\
\text { activity }\end{array}$ & [87] \\
\hline Resveratrol & In vivo skin absorption & Human & $\begin{array}{l}\text { Topically applied resveratrol mainly } \\
\text { located in SC layer }\end{array}$ & [88] \\
\hline Resveratrol & In vitro photoaging & $\mathrm{HaCaT}$ cells & $\begin{array}{l}\text { Resveratrol increased cell survival } \\
\text { and attenuated ROS in UVB-treated } \\
\text { cells }\end{array}$ & [90] \\
\hline Resveratrol & In vivo photoaging & Hairless mouse & $\begin{array}{l}\text { Resveratrol downregulated cell cycle } \\
\text { regulatory proteins }\end{array}$ & [91] \\
\hline Resveratrol & In vivo photoaging & Hairless mouse & Resveratrol downregulated survivin & [92] \\
\hline Pterostilbene & In vitro photoaging & HaCaT cells & $\begin{array}{l}\text { Resveratrol attenuated UVB-evoked } \\
\text { cell death and ROS generation via } \\
\text { Nrf2 signaling }\end{array}$ & [93] \\
\hline Pterostilbene & In vivo photodamage & Hairless mouse & $\begin{array}{l}\text { Pterostilbene showed superior } \\
\text { oxidative damage inhibition than } \\
\text { resveratrol }\end{array}$ & [95] \\
\hline Polydatin & $\begin{array}{l}\text { In vitro and in vivo } \\
\text { photoaging }\end{array}$ & $\begin{array}{l}\mathrm{HaCaT} \text { cells and } \\
\text { nude mouse }\end{array}$ & $\begin{array}{l}\text { Polydatin as the antioxidant and } \\
\text { sunscreen to inhibit UVB-induced } \\
\text { skin damage }\end{array}$ & [96] \\
\hline Oligomers & $\begin{array}{l}\text { In vitro IL-1 } \beta \text {-induced } \\
\text { aging }\end{array}$ & Dermal fibroblasts & $\begin{array}{l}\text { (-)-Hopeaphenol, vaticanol C, } \\
\text { stenophyllol C exhibited significant } \\
\text { inhibition on MMP-1 }\end{array}$ & [36] \\
\hline $\begin{array}{l}\text { Resveratrol in } \\
\text { transfersomes and } \\
\text { ethosomes }\end{array}$ & In vitro $\mathrm{H}_{2} \mathrm{O}_{2}$ treatment & HaCaT cells & $\begin{array}{l}\text { Ethosomes reduced ROS production } \\
\text { and increased resveratrol absorption }\end{array}$ & [99] \\
\hline $\begin{array}{l}\text { Resveratrol in } \\
\text { transfersomes }\end{array}$ & In vitro skin permeation & Strat-M membrane & $\begin{array}{l}\text { Transfersomes increased resveratrol } \\
\text { delivery }\end{array}$ & [100] \\
\hline $\begin{array}{l}\text { Resveratrol in SLNs and } \\
\text { NLCs }\end{array}$ & $\begin{array}{l}\text { In vitro } \mathrm{H}_{2} \mathrm{O}_{2} \text { treatment } \\
\text { and skin permeation }\end{array}$ & Dermal fibroblasts & $\begin{array}{l}\text { NLCs showed greater ROS } \\
\text { reduction than SLNs }\end{array}$ & [102] \\
\hline Resveratrol & In vivo skin atrophy & Sod $^{-1-}$ mouse & $\begin{array}{l}\text { Resveratrol reversed skin thinning } \\
\text { via Sirt1 upregulation }\end{array}$ & [106] \\
\hline Resveratrol & In vivo skin hydration & Human & $\begin{array}{l}\text { Resveratrol increased skin hydration } \\
\text { by } 2 \text {-fold }\end{array}$ & [107] \\
\hline $\begin{array}{l}\text { Resveratrol and } \\
\text { procyanidins }\end{array}$ & $\begin{array}{l}\text { In vivo skin hydration and } \\
\text { elasticity }\end{array}$ & Human & $\begin{array}{l}\text { Skin moisturization and elasticity } \\
\text { were increased by dietary } \\
\text { supplementation }\end{array}$ & [108] \\
\hline Pterostilbene & $\begin{array}{l}\text { In vivo skin hydration and } \\
\text { brightness }\end{array}$ & Human & $\begin{array}{l}\text { The skin moisturization and } \\
\text { elasticity were improved with no } \\
\text { adverse effects }\end{array}$ & [109] \\
\hline $\begin{array}{l}\text { Resveratrol in SLNs, } \\
\text { NLCs, and } \\
\text { nanoemulsions }\end{array}$ & In vivo skin hydration & Human & $\begin{array}{l}\text { An increase of skin hydration was } \\
\text { detected with a tendency of SLNs }> \\
\text { NLCs }>\text { nanoemulsions }\end{array}$ & [111] \\
\hline
\end{tabular}

IL, interleukin; MMP-1, matrix metalloproteinase-1; NLCs, nanostructured lipid carriers; Nrf2, nuclear factor erythroid 2-related factor 2; ROS, reactive oxygen species; SC, stratum corneum; SLNs, solid lipid nanoparticles; Sod: superoxide dismutase; UVB, ultraviolet B.

diminished to $0.21 \mathrm{~mm}$ by topical resveratrol delivery. This thickness approximated the healthy control $(0.22 \mathrm{~mm})$ group. It was reported that ear weight was significantly lesser in the topical resveratrol group $(6.3 \mathrm{mg})$ as compared to the TPA treated group $(9.4 \mathrm{mg})$.

Resveratrol-enriched rice is developed by genetic engineering to combine the properties of resveratrol and rice [119]. Kang et al. [120] used dinitrochlorobenzene (DNCB)-induced AD-like mouse model to evaluate the amount of inflammatory inhibition caused by resveratrol-enriched rice. The rice intake reduced scratching frequency, dermatitis severity, and transepidermal water loss (TEWL) in the DNCB-treated mouse. Topical treatment with the rice remarkably decreased immunoglobulin $\mathrm{E}$ level by $80 \%$. In the cell-based analysis, the rice and resveratrol inhibited IL-1 $\beta$ and IL- 6 expression in $\mathrm{HaCaT}$ cells with a negligible cytotoxicity. Sozmen et al. [121] also assessed the effects of orally delivered resveratrol $(30 \mathrm{mg} / \mathrm{kg}$ per day) on dinitrofluorobenzene (DNFB)-induced AD-like lesion. The results demonstrated that DNFB treatment elevated epidermal thickness of Balb/c mouse from 20 to 97 $\mu \mathrm{m}$. This thickness elevation was lowered to $41 \mu \mathrm{m}$ by resveratrol usage. IL-25, IL-33, and thymic stromal lymphopoietin (TSLP) are released from keratinocytes to activate Th2-type immune response. 
According to immunohistochemical analysis, the number of these proteins in epidermis was lower in resveratrol-treated group than that where only DNFB treatment was conducted. Shen and Xu [122] also found that oral resveratrol $(25 \mathrm{mg} / \mathrm{kg})$ downregulated Th2-type cytokines such as IL-4, IL-5, and IL-13; and Th1-type cytokines such as IL-12 and interferon- $\gamma$ in DNCB-induced mouse.

In addition to resveratrol, its methoxylated form pterostilbene has also shown anti-inflammatory potency for dermatitis treatment. Wang et al. [123] found that oral pterostilbene $(500 \mathrm{mg} / \mathrm{kg}$ per day) attenuated erythema, immune cell infiltration and skin thickness in the chromium-induced allergic contact dermatitis as seen in the mouse. Pterostilbene suppressed IL- $1 \beta$ and tumor necrosis factor (TNF)- $\alpha$ expression in epidermis induced by chromium exposure. The cell-based study demonstrated that pterostilbene at $20 \mu \mathrm{M}$ protected $\mathrm{HaCaT}$ cells against chromium-induced apoptosis and cell death. Pterostilbene decreased ROS production and cytokine expression through activation of p38 MAPK signaling pathway. The molecular mechanism associated with inhibition of inflammation by polydatin was elucidated in primary human keratinocytes [124]. Polydatin significantly suppressed lipopolysaccharide- and TNF- $\alpha$ /interferon- $\gamma$ induced ERK phosphorylation and NF- $\mathrm{KB}$ activation, whereas IL-8 was upregulated by this glycoside under the stimulation of transforming growth factor (TGF)- $\alpha$. HaCaT cell lines were activated by TGF- $\alpha$, promoting the anti-inflammatory mechanism of polydatin [125]. Polydatin at a dose between 10-50 $\mu \mathrm{M}$ downregulated monocyte chemotactic protein (MCP)-1, TNF- $\alpha$, and IL-6 through ERK pathway. The cytokines such as TNF- $\alpha$, IL-6, and IL-8 which were elevated by heat-stressed $\mathrm{HaCaT}$ cells and reduced with polydatin $(44 \mu \mathrm{M})$ treatment [126]. All these data support the fact that polydatin can act as a potential anti-inflammatory agent.

The nanoformulation is a strategy to increase the anti-inflammatory activity of resveratrol. Caddeo et al. [127] developed the liposomes loaded with both resveratrol and quercetin for mitigating inflammatory and oxidative responses in skin. The liposomes exhibited a mean diameter of about $80 \mathrm{~nm}$ with the entrapment percentage of $>70 \%$ in both the compounds. The intracellular concentration in dermal fibroblasts was increased by 4.4- and 4.7-fold after liposomal encapsulation of resveratrol and quercetin respectively. TPA treatment on CD-1 mouse skin caused dry and thickened lesion. TPA-induced edema was decreased by both compounds, especially the liposomes approaching 50\% reduction. Myeloperoxidase activity was inhibited by $80 \%$ after topical liposome application, indicating an inhibited neutrophil infiltration. Niosomes are nanovesicles mainly composed of non-ionic surfactants and cholesterol. These vesicles have a bilayer structure simulating liposomes. Niosomes can be an alternative of liposomes with the advantage of low cost and easy large-scale preparation [128]. Resveratrolloaded niosomes were prepared by thin-film method to test anti-inflammatory action on skin [129]. The vesicle size ranged between 214 and 332 $\mathrm{nm}$ with an encapsulation efficiency of $>45 \%$. The skin deposition as determined by in vitro rat skin showed an outcome of 4.76 and $0.98 \mu \mathrm{g} / \mathrm{cm}^{2}$ for niosomes and aqueous suspension respectively. In vivo anti-inflammatory activity was assessed by carrageenan-induced paw edema. The percentage increase of paw volume for niosomal group was lower than that of saline control group. A prolonged therapeutic efficiency was also observed in the niosomes. Docosahexaenoic acid (DHA) derived from marine origin reveals anti-inflammatory activity which can be used to treat cardiovascular, neurodegenerative, and neoplastic disorders [130]. Serini et al [131] found that DHA loaded in resveratrol-containing SLNs could synergize the inhibition of keratinocyte activation. Free DHA at dose of $30 \mu \mathrm{M}$ suppressed sodium dodecyl sulfate (SDS)induced IL-1 $\beta$ expression in $\mathrm{HaCaT}$ cells resulting in $63 \%$ inhibition. The inhibition was increased to $80 \%$ by encapsulating into resveratrol-loaded SLNs. A similar result was detected by using TNF- $\alpha$ as the stimulator. Resveratrol that was loaded into SLNs inhibited NOD-, LRR- and pyrin domain-containing protein 3 (NLRP3) inflammasome activation and enhancing the anti-inflammatory effect of DHA. In the in vivo contact dermatitis model, resveratrol loaded into SLNs was confirmed to possess the capacity of reducing inflammation [132]. SLNs improved resveratrol delivery into the skin by 3-fold as compared to that of free compound. The SLNs are effectively used in the marketed corticosteroid formulation to restrict edema development. The anti-inflammatory activity of resveratrol and its analogs on keratinocytes or skin is depicted in Table 3. The effects of resveratrol and its analogs on psoriasis and dermatitis for ameliorating the signs and symptoms are listed in Fig. 4.

\subsection{Hyperpigmentation}

Melanin produced by melanocytes gets stored in melanosomes, after which it is deposited in epidermis as the determinant of skin color. Despite the protective effect against sun exposure, abnormal melanin accumulation leads to several disorders 
Table 3. Anti-inflammatory activity of resveratrol and its derivatives.

\begin{tabular}{|c|c|c|c|c|}
\hline Compound & Experimental model & Cell or animal type & Outcomes offered by the compound & Reference \\
\hline Resveratrol & In vitro hyperproliferation & Human keratinocytes & $\begin{array}{l}\text { Resveratrol restrained keratinocyte } \\
\text { proliferation via aquaporin } 3 \\
\text { inhibition }\end{array}$ & [115] \\
\hline Resveratrol & $\begin{array}{l}\text { In vivo psoriasiform } \\
\text { plaque }\end{array}$ & Balb/c mouse & $\begin{array}{l}\text { Oral resveratrol alleviated the } \\
\text { severity of scaling and skin redness }\end{array}$ & [116] \\
\hline Resveratrol & $\begin{array}{l}\text { In vivo psoriasiform } \\
\text { plaque }\end{array}$ & Balb/c mouse & $\begin{array}{l}\text { Topical resveratrol reduced skin } \\
\text { thickness and edema }\end{array}$ & [118] \\
\hline Resveratrol-enriched rice & In vivo $\mathrm{AD}$-like lesion & NC/Nga mouse & $\begin{array}{l}\text { The rice reduced scratching } \\
\text { frequency and dermatitis severity }\end{array}$ & [120] \\
\hline Resveratrol & In vivo $\mathrm{AD}$-like lesion & Balb/c mouse & $\begin{array}{l}\text { Oral resveratrol reduced skin } \\
\text { thickness and immune response }\end{array}$ & [121] \\
\hline Resveratrol & In vivo $\mathrm{AD}$-like lesion & Balb/c mouse & $\begin{array}{l}\text { Oral resveratrol downregulated } \\
\text { Th2-type cytokines }\end{array}$ & [122] \\
\hline Pterostilbene & $\begin{array}{l}\text { In vivo contact dermatitis- } \\
\text { like skin }\end{array}$ & C57BL/6 mouse & $\begin{array}{l}\text { Oral pterostilbene attenuated } \\
\text { erythema and immune cell } \\
\text { infiltration }\end{array}$ & [123] \\
\hline Polydatin & In vitro inflammation & Human keratinocytes & $\begin{array}{l}\text { Polydatin inhibited ERK } \\
\text { phosphorylation and NF- } \kappa B \\
\text { activation }\end{array}$ & [124] \\
\hline Polydatin & In vitro inflammation & HaCaT cells & $\begin{array}{l}\text { Polydatin inhibited MCP-1, TNF- } \alpha \text {, } \\
\text { and IL- } 6\end{array}$ & [125] \\
\hline Polydatin & In vitro inflammation & HaCaT cells & $\begin{array}{l}\text { Polydatin inhibited TNF- } \alpha \text {, IL- } 6 \text {, and } \\
\text { IL- } 8\end{array}$ & [126] \\
\hline $\begin{array}{l}\text { Resveratrol and quercetin } \\
\text { in liposomes }\end{array}$ & $\begin{array}{l}\text { In vitro uptake and in vivo } \\
\text { inflammation }\end{array}$ & $\begin{array}{l}\text { Dermal fibroblasts and } \\
\text { CD-1 mouse }\end{array}$ & $\begin{array}{l}\text { The liposomes increased cellular } \\
\text { uptake and reduced edema and } \\
\text { neutrophil infiltration }\end{array}$ & [127] \\
\hline Resveratrol in niosomes & $\begin{array}{l}\text { In vitro skin absorption } \\
\text { and in vivo inflammation }\end{array}$ & Wistar rat & $\begin{array}{l}\text { The enhanced resveratrol skin } \\
\text { absorption with reduced edema }\end{array}$ & [129] \\
\hline $\begin{array}{l}\text { Resveratrol and DHA in } \\
\text { SLNs }\end{array}$ & In vitro inflammation & $\mathrm{HaCaT}$ cells & $\begin{array}{l}\text { DHA could synergize with } \\
\text { resveratrol in SLNs to inhibit } \\
\text { cytokine expression }\end{array}$ & [131] \\
\hline Resveratrol in SLNs & $\begin{array}{l}\text { In vivo contact dermatitis- } \\
\text { like skin }\end{array}$ & Mouse & SLNs inhibited skin edema & [132] \\
\hline
\end{tabular}

$\mathrm{AD}$, atopic dermatitis; DHA, docosahexaenoic acid; ERK, extracellular signal-regulated kinase; IL, interleukin; MCP-1, monocyte chemotactic protein-1; NF- $\kappa \mathrm{B}$, nuclear factor- $\kappa \mathrm{B}$; SLNs, solid lipid nanoparticles; TNF- $\alpha$, tumor necrosis factor- $\alpha$.

related to hyperpigmentation, including melasma, freckle, age spot, and lentigo [133]. Tyrosinase is a principal enzyme involved in melanogenesis (Fig. 5). Most of the hypopigmenting or skin lightening agents, especially the natural compounds work on the mechanism of tyrosinase inhibition [134]. Resveratrol is a direct tyrosinase inhibitor. It also can inhibit melanogenic enzymes (Fig. 5). Moreover, it can affect keratinocytes that regulate the function of melanocytes. Being an antioxidant, resveratrol prevents keratinocyte-induced melanocyte activation [135]. Park and Boo [136] tested the tyrosinase inhibition caused by resveratrol. It is noticed that treatment of human epidermal melanocytes with tyrosine increased intracellular melanin production. The melanin synthesis was attenuated by resveratrol at a dose of 3-100 $\mu \mathrm{M}$. The HEK293 cells were transformed to express itself as human tyrosinase. It is verified that resveratrol is a strong inhibitor of human tyrosinase with $\mathrm{IC}_{50}$ of $0.39 \mu \mathrm{g} / \mathrm{ml}$, which is lower than p-coumaric acid $(0.66 \mu \mathrm{g} / \mathrm{ml})$ and arbutin
$(>100 \mu \mathrm{g} / \mathrm{ml})$. This skin whitening activity of resveratrol is certified in human [137]. In a study the skin tanning was induced by repetitive UV irradiation on the skin of 15 healthy subjects, followed by the topical administration of resveratrol. The lightness degree $\left(L^{*}\right)$ reduced from 64.2 to 59.3 when treated with resveratrol for 4 days post-irradiation as compared to UV irradiation alone, suggesting that it causes hypopigmentation. Histological assay supported the inhibition of sunburn cell formation when resveratrol intervention was implemented.

Some resveratrol analogs have demonstrated greater capability to inhibit tyrosinase than that seen with resveratrol. Oxyresveratrol has displayed inhibitory effects on mushroom tyrosinase with an $\mathrm{IC}_{50}$ of $1.2 \mu \mathrm{M}$, which was 32 -fold stronger than kojic acid [138]. The $\mathrm{IC}_{50}$ of oxyresveratrol for inhibiting murine tyrosinase activity was $52.7 \mu \mathrm{M}$. Mulberry extract is found to strongly inhibit tyrosinase [139]. Two resveratrol derivatives, namely oxyresveratrol and $4^{\prime}$-prenyloxyresveratrol were isolated from the 


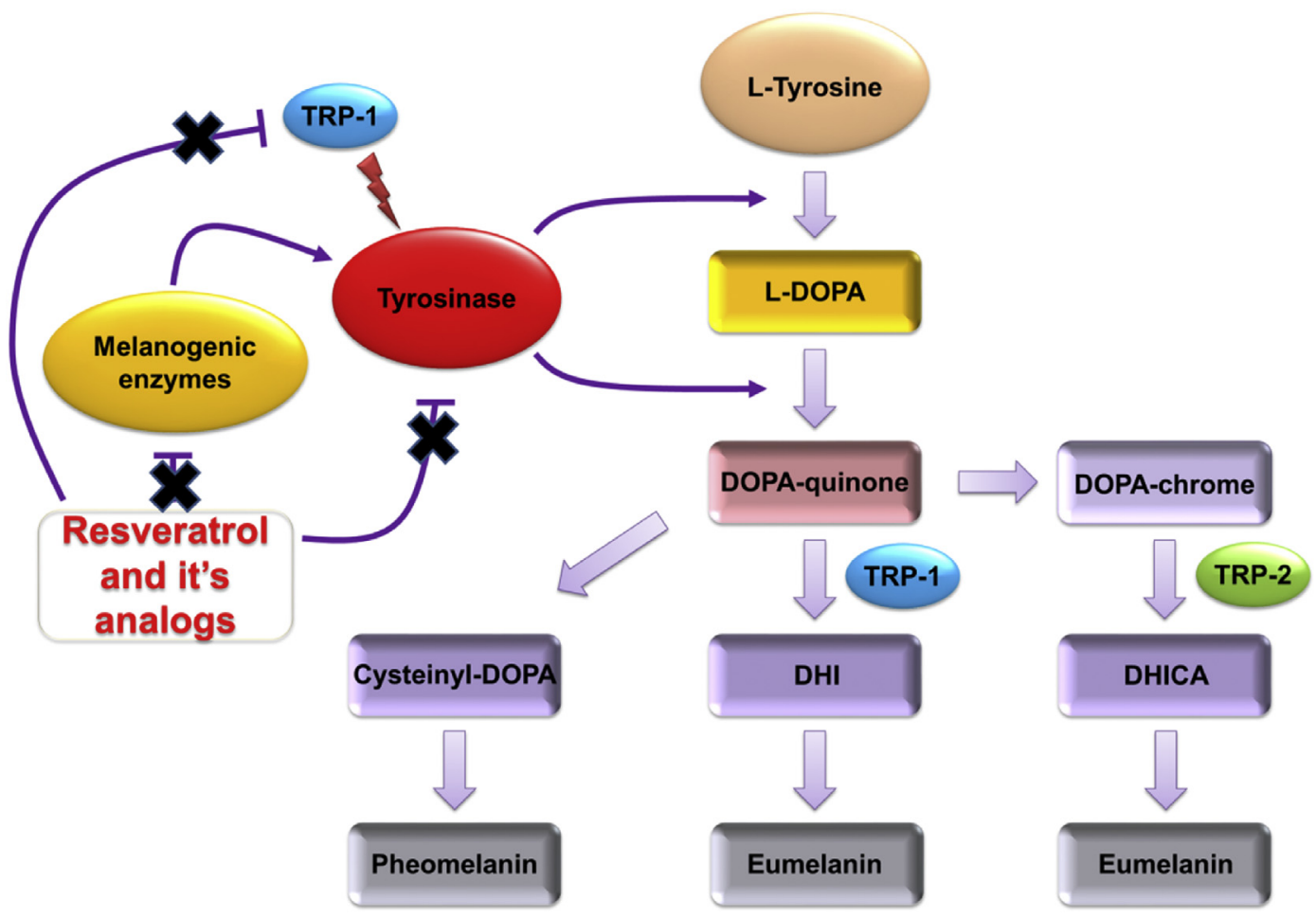

DHI: 5,6-dihydroxyindole

DHICA: 5,6-dihydroxyindole-2-carboxylic acid

L-DOPA: 3,4-dihydroxy-L-phenylalanine ethyl ester

TRP-1: tyrosinase-related protein-1

TRP-2: tyrosinase-related protein-2

Fig. 5. The pathogenic mechanisms of skin hyperpigmentation. Melanin synthesis begins with catalysation of the substrates phenylalanine and tyrosine to produce L-DOPA via tyrosinase. The pathways are then divided into eumelanogenesis or pheomelanogenesis. The other melanogenic enzyme is TRP-1 for eumelanogenesis. Resveratrol is a direct tyrosinase inhibitor. It also can inhibit melanogenic enzymes.

methanol extract of mulberry leaves [140]. The $\mathrm{IC}_{50}$ of oxyresveratrol and $4^{\prime}$-prenyloxyresveratrol required to suppress mushroom tyrosinase was 0.57 and $0.90 \mu \mathrm{M}$ respectively. This inhibitory activity was stronger than that of arbutin $\left(\mathrm{IC}_{50}=14.18 \mu \mathrm{M}\right)$. Park et al. [141] has evaluated the anti-melanogenic potency of oxyresveratrol by using a $3 \mathrm{D}$ reconstituted skin model (MelanoDerm $\left.{ }^{\circledR}\right)$. The reconstituted skin was topically treated with the compounds at a dose of $125 \mu \mathrm{mol}$ per tissue. It was seen that resveratrol and oxyresveratrol lowered melanin amount to $41 \%$ and $65 \%$ respectively. However, the cell viability after undergoing treatment with resveratrol and oxyresveratrol was $20 \%$ and $95 \%$ respectively. This outcome suggested that resveratrol possess high cytotoxicity. In the tyrosinase-transformed HEK293 cell model, oxyresveratrol $\left(\mathrm{IC}_{50}=0.09 \mu \mathrm{M}\right)$ inhibited human tyrosinase strongly as compared to resveratrol $\left(\mathrm{IC}_{50}\right.$ $=1.8 \mu \mathrm{M}$ ). Besides oxyresveratrol, another hydroxylated resveratrol derivative which causes melanogenesis inhibition is piceatannol. The mushroom tyrosinase inhibition caused by piceatannol $\left(\mathrm{IC}_{50}=\right.$ $1.53 \mu \mathrm{M})$ was higher than that of resveratrol $\left(\mathrm{IC}_{50}=\right.$ $63.2 \mu \mathrm{M})$ and kojic acid $\left(\mathrm{IC}_{50}=50.1 \mu \mathrm{M}\right)$ [142]. Piceatannol at a dose of $50 \mu \mathrm{M}$ decreased melanin concentration in B16 cells to $14.8 \%$, which was lower than that of resveratrol $(58.4 \%)$. Piceatannol also exhibited a greater inhibition of reactive oxygen species than that observed with resveratrol.

Jeong et al. [143] explored the inhibitory action of polydatin on melanogenesis. Polydatin at a dosage of 10, 20 and $50 \mu \mathrm{g} / \mathrm{ml}$ decreased melanin level in melan-a melanocytes by about $20 \%, 60 \%$ and $70 \%$ respectively. The enzymes related with melanogenesis such as tyrosinase, tyrosinase-related protein (TRP)-1, and TRP-2 were downregulated by polydatin in a concentration-dependent fashion. The investigation conducted by Uesugi et al. [144] also demonstrated a higher degree of mushroom tyrosinase suppression caused by polydatin $\left(\mathrm{IC}_{50}=14 \mu \mathrm{M}\right)$ as compared with resveratrol $\left(\mathrm{IC}_{50}=565 \mu \mathrm{M}\right)$, implying that glycosylation has improved tyrosinase inhibitory effect. Gnetin $C$ is a resveratrol dimer 
Table 4. Hypopigmenting activity of resveratrol and its derivatives.

\begin{tabular}{|c|c|c|c|c|}
\hline Compound & Experimental model & Cell or animal type & Outcomes offered by the compound & Reference \\
\hline Resveratrol & $\begin{array}{l}\text { Cell-based tyrosinase } \\
\text { inhibition }\end{array}$ & HEK293 cells & $\begin{array}{l}\text { Resveratrol was effective to inhibit } \\
\text { human tyrosinase }\end{array}$ & [136] \\
\hline Resveratrol & In vivo UV irradiation & Human & $\begin{array}{l}\text { Resveratrol inhibited sunburn cell } \\
\text { formation }\end{array}$ & [137] \\
\hline Oxyresveratrol & $\begin{array}{l}\text { Cell-based tyrosinase } \\
\text { inhibition }\end{array}$ & B16 cells & $\begin{array}{l}\text { Oxyresveratrol was effective to } \\
\text { inhibit mushroom and murine } \\
\text { tyrosinases }\end{array}$ & [138] \\
\hline $\begin{array}{l}\text { Oxyresveratrol and } 4^{\prime}- \\
\text { prenyloxyresveratrol }\end{array}$ & $\begin{array}{l}\text { In vitro tyrosinase } \\
\text { inhibition }\end{array}$ & Mushroom tyrosinase & $\begin{array}{l}\text { Oxyresveratrol and } 4^{\prime}- \\
\text { prenyloxyresveratrol from mulberry } \\
\text { inhibited tyrosinase }\end{array}$ & [140] \\
\hline $\begin{array}{l}\text { Resveratrol and } \\
\text { oxyresveratrol }\end{array}$ & $\begin{array}{l}\text { Cell-based 3D } \\
\text { reconstituted skin }\end{array}$ & MelanoDerm $^{\circledR}$ & $\begin{array}{l}\text { Oxyresveratrol showed higher } \\
\text { melanin inhibition than resveratrol }\end{array}$ & [141] \\
\hline $\begin{array}{l}\text { Resveratrol and } \\
\text { piceatannol }\end{array}$ & $\begin{array}{l}\text { In vitro tyrosinase } \\
\text { inhibition }\end{array}$ & $\begin{array}{l}\text { Mushroom tyrosinase } \\
\text { and B16 cells }\end{array}$ & $\begin{array}{l}\text { Piceatannol showed higher } \\
\text { tyrosinase inhibition than } \\
\text { resveratrol }\end{array}$ & [142] \\
\hline Polydatin & $\begin{array}{l}\text { Cell-based tyrosinase } \\
\text { inhibition }\end{array}$ & Melan-a cells & $\begin{array}{l}\text { Polydatin inhibited melanin content } \\
\text { and tyrosinase }\end{array}$ & [143] \\
\hline Polydatin & $\begin{array}{l}\text { In vitro tyrosinase } \\
\text { inhibition }\end{array}$ & Mushroom tyrosinase & $\begin{array}{l}\text { Polydatin showed higher tyrosinase } \\
\text { inhibition than resveratrol }\end{array}$ & [144] \\
\hline Resveratrol and gnectin $C$ & $\begin{array}{l}\text { Cell-based tyrosinase } \\
\text { inhibition }\end{array}$ & B16 cells & $\begin{array}{l}\text { Resveratrol and gnectin showed a } \\
\text { comparable tyrosinase inhibition }\end{array}$ & [145] \\
\hline$\alpha$-Viniferin & $\begin{array}{l}\text { Cell-based tyrosinase } \\
\text { inhibition and in vivo } \\
\text { melasma }\end{array}$ & Melan-a cells and human & $\begin{array}{l}\alpha \text {-Viniferin decreased melanin index } \\
\text { in the patients with melasma }\end{array}$ & [146] \\
\hline $\begin{array}{l}\text { Resveratrol in } \\
\text { nanoparticles }\end{array}$ & In vivo UV irradiation & Guinea pig & $\begin{array}{l}\text { The nanoparticles decreased } \\
\text { melanin granules in skin }\end{array}$ & [147] \\
\hline Resveratrol in SLNs & $\begin{array}{l}\text { In vitro tyrosinase } \\
\text { inhibition }\end{array}$ & Mushroom tyrosinase & $\begin{array}{l}\text { Resveratrol loaded in SLNs } \\
\text { promoted tyrosinase inhibition }\end{array}$ & [148] \\
\hline
\end{tabular}

SLNs, solid lipid nanoparticles; UV, ultraviolet.

which is purified from melinjo seeds. The inhibitory potency of gnetin $C$ and resveratrol was shown to be equally effective against tyrosinase and melanin biosynthesis as observed in the murine B16 cells [145]. The $\mathrm{IC}_{50}$ of gnetin $\mathrm{C}$ activity against tyrosinase and melanin biosynthesis was 7.0 and $7.6 \mu \mathrm{M}$ respectively, whereas resveratrol exerted $\mathrm{IC}_{50}$ of 7.2 and $7.3 \mu \mathrm{M}$ respectively. The anti-melanogenesis response of resveratrol trimer, $\alpha$-viniferin which is present in melanocytes and human skin was evaluated in a study conducted by Yun et al. [146].
Treatment performed with $\alpha$-viniferin in a concentration-dependent manner reduced melanin production in melan-a cells, demonstrating a stronger activity ( $>5$-fold) than that seen in arbutin. In the research twenty-three patients who had melasma and freckles were treated with topically applied Caragana sinica cream which is rich in $\alpha$-viniferin. After 6-8 weeks it was observed that after the treatment with $C$. sinica cream there was a decrease in melanin index and lightening index was increased as

Table 5. Antimicrobial activity of resveratrol and its derivatives.

\begin{tabular}{|c|c|c|c|c|}
\hline Compound & Experimental model & $\begin{array}{l}\text { Microbial or animal } \\
\text { type }\end{array}$ & Outcomes offered by the compound & Reference \\
\hline Resveratrol & In vitro susceptibility & Dermatophytes & $\begin{array}{l}\text { Resveratrol effectively retarded } \\
\text { dermatophyte growth }\end{array}$ & [152] \\
\hline Resveratrol & In vivo skin infection & HSV & $\begin{array}{l}\text { Resveratrol mitigated skin lesion } \\
\text { caused by HSV }\end{array}$ & [155] \\
\hline Oxyresveratrol & In vivo skin infection & HSV & $\begin{array}{l}\text { Oxyresveratrol delayed the } \\
\text { development of skin lesion caused by } \\
\text { HSV }\end{array}$ & [156] \\
\hline Pterostilbene & $\begin{array}{l}\text { In vitro susceptibility and } \\
\text { in vivo skin infection }\end{array}$ & MRSA & $\begin{array}{l}\text { Pterostilbene showed superior MRSA } \\
\text { growth inhibition than resveratrol }\end{array}$ & [157] \\
\hline $\begin{array}{l}\text { Resveratrol and gallic } \\
\text { acid in liposomes }\end{array}$ & $\begin{array}{l}\text { In vitro skin absorption } \\
\text { and microbial inhibition }\end{array}$ & Skin pathogens & $\begin{array}{l}\text { Liposomes improved antimicrobial } \\
\text { activity of resveratrol }\end{array}$ & [158] \\
\hline
\end{tabular}

HSV, herpes simplex virus; MRSA, methicillin-resistant Staphylococcus aureus. 
recorded by chromameter. The response was much better than the vehicle control group.

The resveratrol-enriched rice was grounded to nano-sized particles by applying high pressure homogenization [147]. The average particle size of the products was approximately $500 \mathrm{~nm}$. The nanoparticles were topically applied on UVB-exposed guinea pig skin for 15 days. The results showed that the color index of UVB-treated skin was 72.2 which decreased to 55.1 due to the presence of nanoparticles for 15 days. The amount of melanin granules in skin increased by 2.6 -fold after UVB irradiation. This increase was attenuated by 1.6 -fold due to the presence of nanoparticles. The deposition of resveratrol in skin was dramatically enhanced by this high pressure homogenization technique. Resveratrol-loaded SLNs were developed to examine skin delivery and tyrosinase inhibition [148]. The prepared nanoformulations had a mean diameter of $<200 \mathrm{~nm}$. It is noticed that up to $45 \%$ of resveratrol could permeate through pig skin from SLNs. The tyrosinase inhibitory percentage was increased from $63 \%$ to $90 \%$ after resveratrol entrapment into SLNs. An additional advantage of using the SLNs is that the nanocarriers are non-toxic towards keratinocytes. It is difficult to compare the $\mathrm{IC}_{50}$ of resveratrol and its derivatives since the methodology and experimental setup of different investigations varies. Table 4 summarizes the tyrosinase inhibitory or anti-melanogenesis activity of resveratrol and its derivatives.

\subsection{Microbial infection}

Microorganisms including viruses, bacteria, fungi and parasites can cause infectious diseases. Infection-related illness is a leading cause of death globally [149]. Microbial infection is usually associated with an inflammatory response because it activates immune cell defense against the pathogens. The treatment done with active agents which possess anti-inflammatory and antimicrobial effects will lead to favorable outcomes and will help in alleviating many cutaneous conditions. For instance, more than $90 \%$ of $\mathrm{AD}$ patients are colonized with Staphylococcus aureus [150]. The occurrence of $S$. aureus has emerged as a predominant threat for $\mathrm{AD}$ treatment. Efficient $\mathrm{AD}$ management requires involvement of multiple drug treatments, including the immunomodulatory agents or steroids for antiinflammation and antibiotics for reducing infection [151]. Resveratrol is a phytoalexin that helps to retard the growth of pathogens such as bacteria, fungi, and viruses [114]. Resveratrol could inhibit the growth of some dermatophytes, including
Trichophyton mentagrophytes, T. tonsurans, T. rubrum, Epidermophyton floccosum, and Microsporum gypseum [152]. The effective resveratrol concentration to inhibit growth of these dermatophytes is 110-220 $\mu \mathrm{M}$. Resveratrol is reported to bind ATP synthase, suppressing ATP hydrolysis and synthesis function to inhibit microbial growth [62]. Resveratrol also shows antivirulence nature via biofilm reduction, bacterial motility inhibition, and quorum sensing interference [153]. At this dose range resveratrol is expected to not induce cytotoxicity against human fibroblasts. Along with the antifungal activity, resveratrol effectively displays anti-herpes simplex virus (HSV) potency in skin [154]. Docherty et al. [155] applied topical resveratrol cream $(12.5 \%$ or $25 \%)$ to SKH1 mouse bearing HSV-1 infection. The results demonstrated that when the treatment outcome was evaluated 1 and $6 \mathrm{hrs}$ after infection, both creams effectively suppressed lesion development. The creams are also advantageous to treat acyclovir-resistant HSV. No erythema, scaling, or excoriation was observed in the healthy skin which were treated by resveratrol.

Anti-HSV activity was also found in oxyresveratrol. Chuanasa et al. [156] has evaluated the therapeutic efficiency of topically applied oxyresveratrol on cutaneous HSV infection as observed in Balb/c mouse. Oxyresveratrol $(50 \mu \mathrm{g} / \mathrm{ml})$ caused viral inhibitions of $26 \%$ and $33 \%$ in the infected vero cells when applied for 3 and $6 \mathrm{hrs}$ respectively. The combination of resveratrol and acyclovir created a synergistic anti-HSV-1 response. Topical administration of resveratrol ointment $(30 \%)$ for five times in a day delayed the development of cutaneous lesion caused by HSV-1. Yang et al. [157] investigated the antibacterial activity of pterostilbene against methicillin-resistant $S$. aureus (MRSA) and the feasibility to treat cutaneous lesion and barrier dysfunction. The minimum inhibitory concentration (MIC) assay demonstrated a superior biocidal activity of pterostilbene compared to that of resveratrol (8-16-fold) against MRSA. Pterostilbene was found to reduce MRSA biofilm thickness from 18 to $10 \mu \mathrm{m}$ as detected by confocal microscopy. Pterostilbene increased skin absorption by 6 -fold as compared to resveratrol. Topical pterostilbene application decreased the abscess formation produced by MRSA by reducing the bacterial burden and ameliorating the skin architecture. Pterostilbene demonstrated potent anti-MRSA ability due to the involvement of various mechanisms. Firstly, it enhanced bacterial membrane leakage. Secondly, it caused downregulation of chaperone protein and upregulated ribosomal protein. 
Nanovesicles were used to load resveratrol for increasing its skin delivery and antimicrobial activity. Vitonyte et al. [158] loaded both resveratrol and gallic acid in liposomes to produce vesicles with a size of around $70 \mathrm{~nm}$. A further incorporation of propylene glycol or glycerin as the permeation enhancer increased the size to $170 \mathrm{~nm}$. It was reported that resveratrol accumulation in the dermal layer of pig skin was greater for the glycerin-containing liposomes $(1 \%)$ than that of liposomes and propylene glycol-containing liposomes $(0.4 \%)$. An improvement in antimicrobial activity was shown against skin pathogens such as S. aureus, S. intermedius, S. pyogenes and Candida albicans. Table 5 summarizes the antimicrobial activity of resveratrol and its derivatives, including the design of nanocarriers.

\section{Conclusion}

The clinical application of resveratrol still poses a challenge because of its poor solubility, low bioavailability and the concern of demonstrating adverse effects. The low bioavailability of resveratrol can be due to the limited gastrointestinal absorption and its rapid metabolism. Furthermore, some systemic toxic effects such as headache, somnolence, blood electrolyte change and rash are observed after receiving high-dose resveratrol. Topical delivery of resveratrol can be used as a strategy to avoid the low oral bioavailability and other possible side effects. The topical administration is a preferable method to treat skin-related diseases as discussed in this review. Some of the resveratrol derivatives have demonstrated superior bioactivity than the parent compound while treating skin disorders. Although many resveratrol products are being developed for testing in cell- and animal-based studies, but clinical trials for skin application are still limited. This may be due to the high cost which is required to perform clinical trials and some unknown side effects that should be identified and explored before it is tested clinically. Further clinical studies are required to encourage application of resveratrol and its naturally occurring derivatives in the future.

\section{Conflicts of interest}

The authors have no conflicts of interest.

\section{Acknowledgements}

The authors are grateful to the financial support from Chang Gung Memorial Hospital (CMRPD1G0411-2) and Chi Mei Medical Center (108-CM-FJU-03).

\section{References}

[1] Cory H, Passarelli S, Szeto J, Tamez M, Mattei J. The role of polyphenols in human health and food systems: a minireview. Front Nutr 2018;5:87. https://doi.org/10.3389/ fnut.2018.00087.

[2] Hardman WE. Diet components can suppress inflammation and reduce cancer risk. Nutr Res Pract 2014;8:233-40. https://doi.org/10.4162/nrp.2014.8.3.233.

[3] Baur JA, Sinclair DA. Therapeutic potential of resveratrol: the in vivo evidence. Nat Rev Drug Discov 2006;5:493-506. https://doi.org/10.1038/nrd2060.

[4] Siemann EH, Creasy LL. Concentration of the phytoalexin resveratrol in wine. Am J Enol Vitic 1992;43:49-52.

[5] Kalantari H, Das Dipak K. Physiological effects of resveratrol. Bio Factors 2010;36:401-6. https://doi.org/10.1002/ biof.100.

[6] Meng X, Zhou J, Zhao CN, Gan RY, Li HB. Health benefits and molecular mechanisms of resveratrol: a narrative review. Foods 2020;9:E340. https://doi.org/10.3390/ foods 9030340 .

[7] Koushki M, Lakzaei M, Khodabandehloo H, Hosseini H, Meshkani R, Panahi G. Therapeutic effect of resveratrol supplementation on oxidative stress: a systematic review and meta-analysis of randomised controlled trials. Postgrad Med J 2020;96:197-205. https://doi.org/10.1136/postgradmedj-2019-136415.

[8] Gianchecchi E, Fierabracci A. Insights on the effects of resveratrol and some of its derivatives in cancer and autoimmunity: a molecule with a dual activity. Antioxidants 2020;9:91. https://doi.org/10.3390/antiox9020091.

[9] Biasutto L, Mattarei A, Azzolini M, La Spina M, Sassi N, Romio M, Paradisi C, Zoratti M. Resveratrol derivatives as a pharmacological tool. Ann N Y Acad Sci 2017;1403:27-37. https://doi.org/10.1111/nyas.13401.

[10] Walle T. Bioavailability of resveratrol. Ann N Y Acad Sci 2011;1215:9-15. 6632.2010.05842.x

[11] Francioso A, Mastromarino P, Masci A, d'Erme M, Mosca L. Chemistry, stability and bioavailability of resveratrol. Med Chem 2014;10:237-45. https://doi.org/10.2174/ 15734064113096660053.

[12] Hung CF, Lin YK, Huang ZR, Fang JY. Delivery of resveratrol, a red wine polyphenol, from solutions and hydrogels via the skin. Biol Pharm Bull 2008;31:955-62. https:// doi.org/10.1248/bpb.31.955.

[13] Moyano-Mendez JR, Fabbrocini G, De Stefano D, Mazzella C, Mayol L, Scognamiglio I, Carnuccio R, Ayala F, La Rotonda MI, De Rosa G. Enhanced antioxidant effect of trans-resveratrol: potential of binary systems with polyethylene glycol and cyclodextrin. Drug Dev Ind Pharm 2014; 40:1300-7. https://doi.org/10.3109/03639045.2013.817416.

[14] Tsai MJ, Lu IJ, Fu YS, Fang YP, Huang YB, Wu PC. Nanocarriers enhance the transdermal bioavailability of resveratrol: In-vitro and in-vivo study. Colloids Surf B Biointerfaces 2016;148:650-6. https://doi.org/10.1016/ j.colsurfb.2016.09.045.

[15] Santos AC, Pereira I, Pereira-Silva M, Ferreira L, Caldas M, Collado-González M, Magalhães M, Figueiras A, Ribeiro AJ, Veiga F. Nanotechnology-based formulations for resveratrol delivery: effects on resveratrol in vivo bioavailability and bioactivity. Colloids Surf B Biointerfaces 2019; 180:127-40. https://doi.org/10.1016/j.colsurfb.2019.04.030.

[16] Summerlin N, Soo E, Thakur S, Qu Z, Jambhrunkar S, Popat A. Resveratrol nanoformulations: challenges and opportunities. Int J Pharm 2015;479:282-90. https://doi.org/ 10.1016/j.ijpharm.2015.01.003.

[17] Szekeres T, Fritzer-Szekeres M, Saiko P, Jäger W. Resveratrol and resveratrol analogues-structure-activity relationship. Pharm Res 2010;27:1042-8. https://doi.org/10.1007/ s11095-010-0090-1. 
[18] Nawaz W, Zhou Z, Deng S, Ma X, Ma X, Li C, Shu X. Therapeutic versatility of resveratrol derivatives. Nutrients 2017;9:1188. https://doi.org/10.3390/nu9111188.

[19] Lee HS, Kim DH, Hong JE, Lee JY, Kim EJ. Oxyresveratrol suppresses lipopolysaccharide-induced inflammatory responses in murine macrophages. Hum Exp Toxicol 2015;34: 808-18. https://doi.org/10.1177/0960327114559989.

[20] Choi HY, Lee JH, Jegal KH, Cho IJ, Kim YW, Kim SC. Oxyresveratrol abrogates oxidative stress by activating ERK-Nrf2 pathway in the liver. Chem Biol Interact 2016;245: 110-21. https://doi.org/10.1016/j.cbi.2015.06.024.

[21] Boo YC. Human skin lightening efficacy of resveratrol and its analogs: from in vitro studies to cosmetic applications. Antioxidants 2019;8:332. https://doi.org/10.3390/ antiox 8090332.

[22] Kershaw J, Kim KH. The therapeutic potential of piceatannol, a natural stilbene, in metabolic diseases: a review. J Med Food 2017;20:427-38. https://doi.org/10.1089/ jmf.2017.3916.

[23] Tsai HY, Ho CT, Chen YK. Biological actions and molecular effects of resveratrol, pterostilbene, and 3'-hydroxypterostilbene. J Food Drug Anal 2017;25:134-47. https://doi.org/ 10.1016/j.jfda.2016.07.004.

[24] Paul S, DeCastro AJ, Lee HJ, Smolarek AK, So JY, Simi B, Wang CX, Zhou R, Rimando AM, Suh N. Dietary intake of pterostilbene, a constituent of blueberries, inhibits the betacatenin/p65 downstream signaling pathway and colon carcinogenesis in rats. Carcinogenesis 2010;31:1272-8. https://doi.org/10.1093/carcin/bgq004.

[25] Murias M, Jäger W, Handler N, Erker T, Horvath Z, Szekeres T, Nohl H, Gille L. Antioxidant, prooxidant and cytotoxic activity of hydroxylated resveratrol analogues: structure-activity relationship. Biochem Pharmacol 2005;69: 903-12. https://doi.org/10.1016/j.bcp.2004.12.001.

[26] Chen RJ, Lee YH, Yeh YL, Wu WS, Ho CT, Li CY, Wang BJ, Wang YJ. Autophagy-inducing effect of pterostilbene: a prospective therapeutic/preventive option for skin diseases. J Food Drug Anal 2017;25:125-33. https://doi.org/10.1016/ j.jfda.2016.10.022.

[27] Trobo-Maseda L, Orrego AH, Guisan JM, Rocha-Martín J. Coimmobilization and colocalization of a glycosyltransferase and a sucrose synthase greatly improves the recycling of UDP-glucose: glycosylation of resveratrol $3-\mathrm{O}-\beta-\mathrm{D}-$ glucoside. Int J Biol Macromol 2020;157:510-21. https://doi.org/ 10.1016/j.ijbiomac.2020.04.120.

[28] Şöhretoğlu D, Baran MY, Arroo R, Kuruüzüm-Uz A. Recent advances in chemistry, therapeutic properties and sources of polydatin. Phytochem Rev 2018;17:973-1005. https:// doi.org/10.1007/s11101-018-9574-0.

[29] Su D, Cheng Y, Liu M, Liu D, Cui H, Zhang B, Zhou S, Yang $\mathrm{T}$, Mei Q. Comparision of piceid and resveratrol in antioxidation and antiproliferation activities in vitro. PLoS One 2013;8:e54505. https://doi.org/10.1371/journal.pone.0054505.

[30] Liu WB, Hu L, Hu Q, Chen NN, Yang QS, Wang FF. New resveratrol oligomer derivatives from the roots of Rheum lhasaense. Molecules 2013;18:7093-102. https://doi.org/ 10.3390/molecules18067093.

[31] Snyder SA, Gollner A, Chiriac MI. Regioselective reactions for programmable resveratrol oligomer synthesis. Nature 2011;474:461-6. https://doi.org/10.1038/nature10197.

[32] Shen J, Zhou Q, Li P, Wang Z, Liu S, He C, Zhang C, Xiao P. Update on phytochemistry and pharmacology of naturally occurring resveratrol oligomers. Molecules 2017;22:2050. https://doi.org/10.3390/molecules22122050.

[33] Meneses-Gutiérrez CL, Hernández-Damián J, PedrazaChaverri J, Guerrero-Legarreta I, Téllez DI, Jaramillo-Flores ME. Antioxidant capacity and cytotoxic effects of catechins and resveratrol oligomers produced by enzymatic oxidation against T24 human urinary bladder cancer cells. Antioxidants 2019;8:214. https://doi.org/10.3390/antiox8070214.

[34] Sasikumar P, Lekshmy K, Sini S, Prabha B, Kumar NA, Sivan VV, Jithin MM, Jayamurthy P, Shibi IG, Radhakrishnan KV. Isolation and characterization of resveratrol oligomers from the stem bark of Hopea ponga (Dennst.) Mabb. and their antidiabetic effect by modulation of digestive enzymes, protein glycation and glucose uptake in L6 myocytes. J Ethnopharmacol 2019;236:196-204. https:// doi.org/10.1016/j.jep.2019.01.046.

[35] Ito T, Akao Y, Yi H, Ohguchi K, Matsumoto K, Tanaka T, linuma M, Nozawa Y. Antitumor effect of resveratrol oligomers against human cancer cell lines and the molecular mechanism of apoptosis induced by vaticanol C. Carcinogenesis 2003;24:1489-97. https://doi.org/10.1093/carcin/ bgg105.

[36] Abe N, Ito T, Ohguchi K, Nasu M, Masuda Y, Oyama M, Nozawa $Y$, Ito $M$, linuma M. Resveratrol oligomers from Vatica albiramis. J Nat Prod 2010;73:1499-506. https:// doi.org/10.1021/np1002675.

[37] Chuang SY, Lin YK, Lin CF, Wang PW, Chen EL, Fang JY. Elucidating the skin delivery of aglycone and glycoside flavonoids: how the structures affect cutaneous absorption. Nutrients 2017;9:1304. https://doi.org/10.3390/nu9121304.

[38] Rzhevskiy AS, Guy RH, Anissimov YG. Modelling drug flux through microporated skin. J Control Release 2016;241: 194-9. https://doi.org/10.1016/j.jconrel.2016.09.029.

[39] Karimkhani C, Dellavalle RP, Coffeng LE, Flohr C, Hay RJ, Langan SM, Nsoesie EO, Ferrari AJ, Erskine HE, Silverberg JI, Vos T, Naghavi M. Global skin disease morbidity and mortality: an update from the global burden of disease study 2013. JAMA Dermatol 2017;153:406-12. https:// doi.org/10.1001/jamadermatol.2016.5538.

[40] Hsiao CY, Yang SC, Alalaiwe A, Fang JY. Laser ablation and topical drug delivery: a review of recent advances. Expert Opin Drug Deliv 2019;16:937-52. https://doi.org/10.1080/ 17425247.2019.1649655.

[41] Ratz-Łyko A, Arct J. Resveratrol as an active ingredient for cosmetic and dermatological applications: a review. J Cosmet Laser Ther 2019;21:84-90. https://doi.org/10.1080/ 14764172.2018.1469767.

[42] Apalla Z, Lallas A, Sotiriou E, Lazaridou E, Ioannides D. Epidemiological trends in skin cancer. Dermatol Pract Concept 2017;7:1-6. https://doi.org/10.5826/dpc.0702a01.

[43] Lv R, Sun Q. A network meta-analysis of non-melanoma skin cancer (NMSC) treatments: efficacy and safety assessment. J Cell Biochem 2017;118:3686-95. https://doi.org/ 10.1002/jcb.26015.

[44] Costa A, Bonner MY, Arbiser JL. Use of polyphenolic compounds in dermatologic oncology. Am J Clin Dermatol 2016;17:369-85. https://doi.org/10.1007/s40257-016-0193-5.

[45] Narayanan DL, Saladi RN, Fox JL. Ultraviolet radiation and skin cancer. Int J Dermatol 2010;49:978-86. https://doi.org/ 10.1111/j.1365-4632.2010.04474.x.

[46] de Gruijl FR. UV adaptation: pigmentation and protection against overexposure. Exp Dermatol 2017;26:557-62. https://doi.org/10.1111/exd.13332.

[47] Wagener FA, Carels CE, Lundvig DM. Targeting the redox balance in inflammatory skin conditions. Int J Mol Sci 2013; 14:9126-67. https://doi.org/10.3390/ijms14059126.

[48] Griffiths CEM, van der Walt JM, Ashcroft DM, Flohr C, Naldi L, Nijsten T, Augustin M. The global state of psoriasis disease epidemiology: a workshop report. Br J Dermatol 2017;177:4-7. https://doi.org/10.1111/bjd.15610.

[49] Chuang SY, Lin CH, Sung CT, Fang JY. Murine models of psoriasis and their usefulness for drug discovery. Expert Opin Drug Discov 2018;13:551-62. https://doi.org/10.1080/ 17460441.2018.1463214.

[50] Helmick CG, Lee-Han H, Hirsch SC, Baird TL, Bartlett CL. Prevalence of psoriasis among adults in the U.S.: 2003-2006 and 2009-2010 National Health and Nutrition Examination Surveys. Am J Prev Med 2014;47:37-45. https://doi.org/ 10.1016/j.amepre.2014.02.012.

[51] Farahnik B, Sharma D, Alban J, Sivamani RK. Topical botanical agents for the treatment of psoriasis: a systematic review. Am J Clin Dermatol 2017;18:451-68. https://doi.org/ 10.1007/s40257-017-0266-0. 
[52] Huang TH, Lin CF, Alalaiwe A, Yang SC, Fang JY. Apoptotic or antiproliferative activity of natural products against keratinocytes for the treatment of psoriasis. Int J Mol Sci 2019;20:2558. https://doi.org/10.3390/ijms20102558.

[53] Shaw TE, Currie GP, Koudelka CW, Simpson EL. Eczema prevalence in the United States: data from the 2003 National Survey of Children's Health. J. Invest Dermatol 2011;131: 67-73. https://doi.org/10.1038/jid.2010.251.

[54] Nygaard U, Deleuran M, Vestergaard C. Emerging treatment options in atopic dermatitis: topical therapies. Dermatology 2017;233:333-43. https://doi.org/10.1159/ 1000484407.

[55] Williams HC. Atopic dermatitis. N Engl J Med 2005;352: 2314-24. https://doi.org/10.1056/NEJMcp042803.

[56] Hajar T, Leshem YA, Hanifin JM, Nedorost ST, Lio PA, Paller AS, Block J, Simpson EL. A systematic review of topical corticosteroid withdrawal ("steroid addiction") in patients with atopic dermatitis and other dermatoses. J Am Acad Dermatol 2015;72:541-9. https://doi.org/10.1016/ j.jaad.2014.11.024.

[57] Yun Y, Kim K, Choi I, Ko SG. Topical herbal application in the management of atopic dermatitis: a review of animal studies. Mediators Inflamm 2014;2014:752103. https:// doi.org/10.1155/2014/752103.

[58] van Smeden J, Bouwstra JA. Stratum corneum lipids: their role for the skin barrier function in healthy subjects and atopic dermatitis patients. Curr Probl Dermatol 2016;49: 8-26. https://doi.org/10.1159/000441540.

[59] Ong PY. Recurrent MRSA skin infections in atopic dermatitis. J Allergy Clin Pract 2014;2:396-9. https://doi.org/ 10.1016/j.jaip.2014.04.007.

[60] Shi B, Leung DYM, Taylor PA, Li H. MRSA colonization is associated with decreased skin commensal bacteria in atopic dermatitis. J Invest Dermatol 2018;138:1668-71. https://doi.org/10.1016/j.jid.2018.01.022.

[61] Dandawate P, Padhye S, Schobert R, Biersack B. Discovery of natural products with metal-binding properties as promising antibacterial agents. Expert Opin Drug Discov 2019;14:563-76. 17460441.2019.1593367.

[62] Vestergaard $M$, Ingmer $H$. Antibacterial and antifungal properties of resveratrol. Int J Antimicrob Agents 2019;53: 716-23. https://doi.org/10.1016/j.ijantimicag.2019.02.015.

[63] Passeron T. Melasma pathogenesis and influencing factorsan overview of the latest research. J Eur Acad Dermatol Venereol 2013;27(Suppl. 1):5-6. https://doi.org/10.1111/ jdv.12049.

[64] Satooka H, Kubo I. Resveratrol as a kcat type inhibitor for tyrosinase: potentiated melanogenesis inhibitor. Bioorg Med Chem 2012;20:1090-9. https://doi.org/10.1016/ j.bmc.2011.11.030.

[65] Varoni EM, Lo Faro AF, Sharifi-Rad J, Iriti M. Anticancer molecular mechanisms of resveratrol. Front Nutr 2016;3:8. https://doi.org/10.3389/fnut.2016.00008.

[66] Pezzuto JM. The phenomenon of resveratrol: redefining the virtues of promiscuity. Ann N Y Acad Sci 2011;1215:123-30. https://doi.org/10.1111/j.1749-6632.2010.05849.x.

[67] Aminuddin A, Ng PY. Promising druggable target in head and neck squamous cell carcinoma: Wnt signaling. Front Pharmacol 2016;7:244. https://doi.org/10.3389/ fphar.2016.00244.

[68] Liu ZL, Li H, Liu J, Wu ML, Chen XY, Liu LH, Wang Q. Inactivated Wnt signaling in resveratrol-treated epidermal squamous cancer cells and its biological implication. Oncol Lett 2017;14:2239-43. https://doi.org/10.3892/ol.2017.6458.

[69] Junco JJ, Mancha A, Malik G, Wei SJ, Kim DJ, Liang H, Slaga TJ. Resveratrol and P-glycoprotein inhibitors enhance the anti-skin cancer effects of ursolic acid. Mol Cancer Res 2013;11:1521-9. https://doi.org/10.1158/1541-7786.MCR-130237.

[70] Junco JJ, Cho J, Mancha A, Malik G, Wei SJ, Kim DJ, Liang $\mathrm{H}$, DiGiovanni J, Slaga TJ. Role of AMPK and PPAR $\alpha$ in the anti-skin cancer effects of ursolic acid. Mol Carcinog 2018; 57:1698-706. https://doi.org/10.1002/mc.22890.

[71] Kundu JK, Shin YK, Kim SH, Surh YJ. Resveratrol inhibits phorbol ester-induced expression of COX-2 and activation of NF- $\kappa \mathrm{B}$ in mouse skin by blocking I $\kappa \mathrm{B}$ kinase activity. Carcinogenesis 2006;27:1465-74. https://doi.org/10.1093/ carcin/bgi349.

[72] Kundu JK, Shin YK, Surh YJ. Resveratrol modulates phorbol ester-induced pro-inflammatory signal transduction pathways in mouse skin in vivo: NF- $\kappa$ B and AP-1 as prime targets. Biochem Pharmacol 2006;72:1506-15. https:// doi.org/10.1016/j.bcp.2006.08.005.

[73] Roy P, Kalra N, Prasad S, George J, Shukla Y. Chemopreventive potential of resveratrol in mouse skin tumors through regulation of mitochondrial and PI3K/AKT signaling pathways. Pharm Res 2009;26:211-7. https:// doi.org/10.1007/s11095-008-9723-z.

[74] Heenatigala Palliyage G, Singh S, Ashby Jr CR, Tiwari AK, Chauhan H. Pharmaceutical topical delivery of poorly soluble polyphenols: potential role in prevention and treatment of melanoma. AAPS PharmSciTech 2019;20:250. https://doi.org/10.1208/s12249-019-1457-1.

[75] Gong C, Xia H. Resveratrol suppresses melanoma growth by promoting autophagy through inhibiting the PI3K/AKT/ mTOR signaling pathway. Exp Ther Med 2020;19:1878-86. https://doi.org/10.3892/etm.2019.8359.

[76] Osmond GW, Augustine CK, Zipfel PA, Padussis J, Tyler DS. Enhancing melanoma treatment with resveratrol. J Surg Res 2012;172:109-15. https://doi.org/10.1016/ j.jss.2010.07.033.

[77] Nivelle L, Hubert J, Courot E, Jeandet P, Aziz A, Nuzillard JM, Renault JH, Clément C, Martiny L, Delmas D, Tarpin M. Anti-cancer activity of resvaratrol and derivatives produced by grapevine cell suspensions in a 14 L stirred bioreactor. Molecules 2017;22:474. https://doi.org/10.3390/ molecules22030474.

[78] Nivelle L, Aires V, Rioult D, Martiny L, Tarpin M, Delmas D. Molecular analysis of differential antiproliferative activity of resveratrol, epsilon viniferin and labruscol on melanoma cells and normal dermal cells. Food Chem Toxicol 2018;116:323-34. https://doi.org/10.1016/j.fct.2018.04.043.

[79] Chen R, Li R, Liu Q, Bai C, Qin B, Ma Y, Han J. Ultradeformable liposomes: a novel vesicular carrier for enhanced transdermal delivery of procyanidins: effect of surfactants on the formation, stability, and transdermal delivery. AAPS PharmSciTech 2017;18:1823-32. https:// doi.org/10.1208/s12249-016-0661-5.

[80] Cosco D, Paolino D, Maiuolo J, Marzio LD, Carafa M, Ventura CA, Fresta M. Ultradeformable liposomes as multidrug carrier of resveratrol and 5-fluorouracil for their topical delivery. Int J Pharm 2015;489:1-10. https://doi.org/ 10.1016/j.ijpharm.2015.04.056.

[81] Bano S, Ahmed F, Khan F, Chaudhary SC, Samim M. Enhancement of the cancer inhibitory effect of the bioactive food component resveratrol by nanoparticle based delivery. Food Funct 2020;11:3213-26. https://doi.org/10.1039/ c9fo02445j.

[82] Kohl E, Steinbauer J, Landthaler M, Szeimies RM. Skin ageing. J Eur Acad Dermatol Venereol 2011;25:873-84. https://doi.org/10.1111/j.1468-3083.2010.03963.x.

[83] Farage MA, Miller KW, Elsner P, Maibach HI. Intrinsic and extrinsic factors in skin ageing: a review. Int J Cosmet Sci 2008;30:87-95. 2494.2007.00415.x.

[84] Davinelli S, Bertoglio JC, Polimeni A, Scapagnini G. Cytoprotective polyphenols against chronological skin aging and cutaneous photodamage. Curr Pharm Des 2018;24: 99-105. 1381612823666171109102426

[85] Serravallo M, Jagdeo J, Glick SA, Siegel DM, Brody NI. Sirtuins in dermatology: applications for future research and therapeutics. Arch Dermatol Res 2013;305:269-82. https://doi.org/10.1007/s00403-013-1320-2. 
[86] Truong VL, Jun M, Jeong WS. Role of resveratrol in regulation of cellular defense systems against oxidative stress. Biofactors 2018;44:36-49. https://doi.org/10.1002/ biof.1399.

[87] Alonso C, Rubio L, Touriño S, Martí M, Barba C, Fernández-Campos F, Coderch L, Parra JL. Antioxidative effects and percutaneous absorption of five polyphenols. Free Radic Biol Med 2014;75:149-55. https://doi.org/10.1016/ j.freeradbiomed.2014.07.014.

[88] Alonso C, Martí M, Barba C, Carrer V, Rubio L, Coderch L. Skin permeation and antioxidant efficacy of topically applied resveratrol. Arch Dermatol Res 2017;309:423-31. https://doi.org/10.1007/s00403-017-1740-5.

[89] Parrado C, Mercado-Saenz S, Perez-Davo A, Gilaberte Y, Gonzalez S, Juarranz A. Environmental stressors on skin aging. Mechanistic insights. Front Pharmacol 2019;10:759. https://doi.org/10.3389/fphar.2019.00759.

[90] Park K, Lee JH. Protective effects of resveratrol on UVBirradiated HaCaT cells through attenuation of the caspase pathway. Oncol Rep 2008;19:413-7. https://doi.org/10.3892/ or.19.2.413.

[91] Reagan-Shaw S, Afaq F, Aziz MH, Ahmad N. Modulations of critical cell cycle regulatory events during chemoprevention of ultraviolet $\mathrm{B}$-mediated responses by resveratrol in SKH-1 hairless mouse skin. Oncogene 2004;23:5151-60. https://doi.org/10.1038/sj.onc.1207666.

[92] Aziz MH, Afaq F, Ahmad N. Prevention of ultraviolet-B radiation damage by resveratrol in mouse skin is mediated via modulation in survivin. Photochem Photobiol 2005;81: 25-31. https://doi.org/10.1562/2004-08-13-RA-274.

[93] Li H, Jiang N, Liang B, Liu Q, Zhang E, Peng L, Deng H, Li $\mathrm{R}$, Li Z, Zhu H. Pterostilbene protects against UVB-induced photo-damage through a phosphatidylinositol-3-kinasedependent Nrf2/ARE pathway in human keratinocytes. Redox Rep 2017;22:501-7. https://doi.org/10.1080/ 13510002.2017.1329917.

[94] Ma Q. Role of nrf2 in oxidative stress and toxicity. Ann Rev Pharmacol Toxicol 2013;53:401-26. https://doi.org/10.1146/ annurev-pharmtox-011112-140320.

[95] Sirerol JA, Feddi F, Mena S, Rodriguez ML, Sirera P, Aupí M, Pérez S, Asensi M, Ortega A, Estrela JM. Topical treatment with pterostilbene, a natural phytoalexin, effectively protects hairless mice against UVB radiation-induced skin damage and carcinogenesis. Free Radic Biol Med 2015;85: 1-11. https://doi.org/10.1016/j.freeradbiomed.2015.03.027.

[96] He YD, Liu YT, Lin QX, Zhu J, Zhang Y, Wang LY, Ren XL, Ye XY. Polydatin suppresses ultraviolet B-induced cyclooxygenase- 2 expression in vitro and in vivo via reduced production of reactive oxygen species. Br J Dermatol 2012; 167:941-4. https://doi.org/10.1111/j.1365-2133.2012.10951.x.

[97] Pittayapruek P, Meephansan J, Prapapan O, Komine M, Ohtsuki M. Role of matrix metalloproteinases in photoaging and photocarcinogenesis. Int J Mol Sci 2016;17:868. https://doi.org/10.3390/ijms17060868.

[98] Garg V, Singh H, Bimbrawh S, Singh SK, Gulati M, Vaidya Y, Kaur P. Ethosomes and transfersomes: principles, perspectives and practices. Curr Drug Deliv 2017;14:613-33. https://doi.org/10.2174/1567201813666160520114436.

[99] Scognamiglio I, De Stefano D, Campani V, Mayol L, Carnuccio R, Fabbrocini G, Ayala F, La Rotonda MI, De Rosa G. Nanocarriers for topical administration of resveratrol: a comparative study. Int J Pharm 2013;440:179-87. https:// doi.org/10.1016/j.ijpharm.2012.08.009.

[100] Wu PS, Li YS, Kuo YC, Tsai SJ, Lin CC. Preparation and evaluation of novel transfersomes combined with the natural antioxidant resveratrol. Molecules 2019;24:600. https:// doi.org/10.3390/molecules24030600.

[101] Wen CJ, Yen TC, Al-Suwayeh SA, Chang HW, Fang JY. In vivo real-time fluorescence visualization and brain-targeting mechanisms of lipid nanocarriers with different fatty ester:oil ratios. Nanomedicine 2011;6:1545-59. https:// doi.org/10.2217/nnm.11.46.
[102] Gokce EH, Korkmaz E, Dellera E, Sandri G, Bonferoni MC, Ozer O. Resveratrol-loaded solid lipid nanoparticles versus nanostructured lipid carriers: evaluation of antioxidant potential for dermal applications. Int J Nanomed 2012;7: 1841-50. https://doi.org/10.2147/IJN.S29710.

[103] Gu Y, Han J, Jiang C, Zhang Y. Biomarkers, oxidative stress and autophagy in skin aging. Ageing Res Rev 2020;59: 101036. https://doi.org/10.1016/j.arr.2020.101036.

[104] de Lima Cherubim DJ, Buzanello Martins CV, Oliveira Fariña L, da Silva de Lucca RA. Polyphenols as natural antioxidants in cosmetics applications. J Cosmet Dermatol 2020;19:33-7. https://doi.org/10.1111/jocd.13093.

[105] Kato E, Tokunaga Y, Sakan F. Stilbenoids isolated from the seeds of melinjo (Gnetum gnemon L.) and their biological activity. J Agric Food Chem 2009;57:2544-9. https://doi.org/ 10.1021/jf803077p.

[106] Watanabe K, Shibuya S, Ozawa Y, Izuo N, Shimizu T. Resveratrol derivative-rich melinjo seed extract attenuates skin atrophy in Sod1-deficient mice. Oxid Med Cell Longev 2015;2015:391075. https://doi.org/10.1155/2015/391075.

[107] Igielska-Kalwat J, Firlej M, Lewandowska A, Biedziak B. In vivo studies of resveratrol contained in cosmetic emulsions. Acta Biochim Pol 2019;66:371-4. https://doi.org/10.18388/ abp.2019_2838.

[108] Buonocore D, Lazzeretti A, Tocabens P, Nobile V, Cestone E, Santin G, Bottone MG, Marzatico F. Resveratrol-procyanidin blend: nutraceutical and antiaging efficacy evaluated in a placebocontrolled, double-blind study. Clin Cosmet Invest Dermatol 2012;5:159-65. https://doi.org/ 10.2147/CCID.S36102.

[109] Majeed M, Majeed S, Jain R, Mundkur L, Rajalakshmi HR, Lad PS, Neupane P. An open-label single-arm, monocentric study assessing the efficacy and safety of natural pterostilbene (Pterocarpus marsupium) for skin brightening and antiaging effects. Clin Cosmet Invest Dermatol 2020;13: 105-16. https://doi.org/10.2147/CCID.S238358.

[110] Pardeike J, Hommoss A, Müller RH. Lipid nanoparticles (SLN, NLC) in cosmetic and pharmaceutical dermal products. Int J Pharm 2009;366:170-84. https://doi.org/10.1016/ j.ijpharm.2008.10.003.

[111] Montenegro L, Parenti C, Turnaturi R, Pasquinucci L. Resveratrol-loaded lipid nanocarriers: correlation between in vitro occlusion factor and in vivo skin hydrating effect. Pharmaceutics 2017;9:E58. https://doi.org/10.3390/ pharmaceutics 9040058.

[112] Dainichi T, Hanakawa S, Kabashima K. Classification of inflammatory skin diseases: a proposal based on the disorders of the three-layered defense systems, barrier, innate immunity and acquired immunity. J Dermatol Sci 2014;76: 81-9. https://doi.org/10.1016/j.jdermsci.2014.08.010.

[113] Oliveira ALB, Monteiro VVS, Navegantes-Lima KC, Reis JF, Gomes RS, Rodrigues DVS, Gaspar SLF, Monteiro MC. Resveratrol role in autoimmune disease-A mini-review. Nutrients 2017;9:1306. https://doi.org/10.3390/nu9121306.

[114] Salehi B, Mishra AP, Nigam M, Sener B, Kilic M, SharifiRad M, Fokou PVT, Martins N, Sharifi-Rad J. Resveratrol: a double-edged sword in health benefits. Biomedicines 2018; 6:91. https://doi.org/10.3390/biomedicines6030091.

[115] Wu Z, Uchi H, Morino-Koga S, Shi W, Furue M. Resveratrol inhibition of human keratinocyte proliferation via SIRT1/ ARNT/ERK dependent downregulation of aquaporin 3. J Dermatol Sci 2014;75:16-23. https://doi.org/10.1016/ j.jdermsci.2014.03.004.

[116] Kjær TN, Thorsen K, Jessen N, Stenderup K, Pedersen SB. Resveratrol ameliorates imiquimod-induced psoriasis-like skin inflammation in mice. PLoS One 2015;10:e126599. https://doi.org/10.1371/journal.pone.0126599.

[117] Madsen M, Hansen PR, Nielsen LB, Hartvigsen K, Pedersen AE, Christensen JP, Aarup A, Pedersen TX. Effect of 12-Otetradecanoylphorbol-13-acetate-induced psoriasis-like skin lesions on systemic inflammation and atherosclerosis in hypercholesterolaemic apolipoprotein $\mathrm{E}$ deficient mice. 
BMC Dermatol 2016;16:9. https://doi.org/10.1186/s12895016-0046-1.

[118] Murakami I, Chaleckis R, Pluskal T, Ito K, Hori K, Ebe M, Yanagida M, Kondoh $\mathrm{H}$. Metabolism of skin-absorbed resveratrol into its glucuronized form in mouse skin. PLoS One 2014;9:e115359. https://doi.org/10.1371/ journal.pone.0115359.

[119] Chung HJ, Sharma SP, Kim HJ, Baek SH, Hong ST. The resveratrol-enriched rice DJ526 boosts motor coordination and physical strength. Sci Rep 2016;6:23958. https://doi.org/ $10.1038 /$ srep23958.

[120] Kang MC, Cho K, Lee JH, Subedi L, Yumnam S, Kim SY. Effect of resveratrol-enriched rice on skin inflammation and pruritus in the NC/Nga mouse model of atopic dermatitis. Int J Mol Sci 2019;20:1428. https://doi.org/10.3390/ ijms20061428.

[121] Caglayan Sozmen S, Karaman M, Cilaker Micili S, Isik S, Arikan Ayyildiz Z, Bagriyanik A, Uzuner N, Karaman O. Resveratrol ameliorates 2,4-dinitrofluorobenzene-induced atopic dermatitis-like lesions through effects on the epithelium. PeerJ 2016;4:e1889. https://doi.org/10.7717/ peerj.1889.

[122] Shen $Y, X u$ J. Resveratrol exerts therapeutic effects on mice with atopic dermatitis. Wounds 2019;31:279-84.

[123] Wang BJ, Chiu HW, Lee YL, Li CY, Wang YJ, Lee YH. Pterostilbene attenuates hexavalent chromium-induced allergic contact dermatitis by preventing cell apoptosis and inhibiting IL-1 $\beta$-related NLRP3 inflammasome activation. J Clin Med 2018;7:489. https://doi.org/10.3390/jcm7120489.

[124] Potapovich AI, Lulli D, Fidanza P, Kostyuk VA, De Luca C, Pastore S, Korkina LG. Plant polyphenols differentially modulate inflammatory responses of human keratinocytes by interfering with activation of transcription factors NFKB and AhR and EGFR-ERK pathway. Toxicol Appl Pharmacol 2011;255:138-49. https://doi.org/10.1016/ j.taap.2011.06.007.

[125] Pastore S, Lulli D, Fidanza P, Potapovich AI, Kostyuk VA, De Luca C, Mikhal'chik E, Korkina LG. Plant polyphenols regulate chemokine expression and tissue repair in human keratinocytes through interaction with cytoplasmic and nuclear components of epidermal growth factor receptor system. Antioxid Redox Signal 2012;16:314-28. https:// doi.org/10.1089/ars.2011.4053.

[126] Ravagnan G, De Filippis A, Cartenì M, De Maria S, Cozza V, Petrazzuolo M, Tufano MA, Donnarumma G. Polydatin, a natural precursor of resveratrol, induces $\beta$-defensin production and reduces inflammatory response. Inflammation 2013;36:26-34. https://doi.org/10.1007/s10753-012-9516-8.

[127] Caddeo C, Nacher A, Vassallo A, Armentano MF, Pons R, Fernàndez-Busquets $X$, Carbone $C$, Valenti $D$, Fadda $A M$, Manconi M. Effect of quercetin and resveratrol co-incorporated in liposomes against inflammatory/oxidative response associated with skin cancer. Int J Pharm 2016;513: 153-63. https://doi.org/10.1016/j.ijpharm.2016.09.014.

[128] Moghassemi S, Hadjizadeh A. Nano-niosomes as nanoscale drug delivery systems: an illustrated review. J Control Release 2014;185:22-36. https://doi.org/10.1016/ j.jconrel.2014.04.015.

[129] Negi P, Aggarwal M, Sharma G, Rathore C, Sharma G, Singh B, Katare OP. Niosome-based hydrogel of resveratrol for topical applications: an effective therapy for pain related disorder(s). Biomed Pharmacother 2017;88:480-7. https:// doi.org/10.1016/j.biopha.2017.01.083.

[130] Huang TH, Wang PW, Yang SC, Chou WL, Fang JY. Cosmetic and therapeutic applications of fish oil's fatty acids on the skin. Mar Drugs 2018;16:256. https://doi.org/ $10.3390 / \mathrm{md} 16080256$.

[131] Serini S, Cassano R, Facchinetti E, Amendola G, Trombino S, Calviello G. Anti-irritant and anti-inflammatory effects of DHA encapsulated in resveratrol-based solid lipid nanoparticles in human keratinocytes. Nutrients 2019;11:1400. https://doi.org/10.3390/nu11061400.
[132] Shrotriya SN, Ranpise NS, Vidhate BV. Skin targeting of resveratrol utilizing solid lipid nanoparticle-engrossed gel for chemically induced irritant contact dermatitis. Drug Deliv Transl Res 2017;7:37-52. https://doi.org/10.1007/ s13346-016-0350-7.

[133] Vashi NA, Wirya SA, Inyang M, Kundu RV. Facial hyperpigmentation in skin color: special considerations and treatment. Am J Clin Dermatol 2017;18:215-30. https:// doi.org/10.1007/s40257-016-0239-8.

[134] Zaidi KU, Ali SA, Ali A, Naaz I. Natural tyrosinase inhibitors: role of herbals in the treatment of hyperpigmentary disorders. Mini Rev Med Chem 2019;19: 796-808. 1389557519666190116101039.

[135] Na JI, Shin JW, Choi HR, Kwon SH, Park KC. Resveratrol as a multifunctional topical hypopigmenting agent. Int J Mol Sci 2019;20:956. https://doi.org/10.3390/ijms20040956.

[136] Park J, Boo YC. Isolation of resveratrol from Vitis viniferae caulis and its potent inhibition of human tyrosinase. Evid Based Complement Alternat Med 2013;2013:645257. https:// doi.org/10.1155/2013/645257.

[137] Wu Y, Jia LL, Zheng YN, Xu XG, Luo YJ, Wang B, Chen JZ Gao XH, Chen HD, Matsui M, Li YH. Resveratrate protects human skin from damage due to repetitive ultraviolet irradiation. J Eur Acad Dermatol Venereol 2013;27:345-50. https://doi.org/10.1111/j.1468-3083.2011.04414.x.

[138] Kim YM, Yun J, Lee CK, Lee H, Min KR, Kim Y. Oxyresveratrol and hydroxystilbene compounds. Inhibitory effect on tyrosinase and mechanism of action. J Biol Chem 2002;277:16340-4. https://doi.org/10.1074/ jbc.M200678200.

[139] Chan EW, Lye PY, Wong SK. Phytochemistry, pharmacology, and clinical trials of Morus alba. Chin J Nat Med 2016;14:17-30. https://doi.org/10.3724/SP.J.1009.2016.00017.

[140] Jeon YH, Choi SW. Isolation, identification, and quantification of tyrosinase and $\alpha$-glucosidase inhibitors from UVC-irradiated mulberry (Morus alba L.) leaves. Prev Nutr Food Sci 2019;24:84-94. https://doi.org/10.3746/ pnf.2019.24.1.84.

[141] Park J, Park JH, Suh HJ, Lee IC, Koh J, Boo YC. Effects of resveratrol, oxyresveratrol, and their acetylated derivatives on cellular melanogenesis. Arch Dermatol Res 2014;306: 475-87. https://doi.org/10.1007/s00403-014-1440-3.

[142] Yokozawa T, Kim YJ. Piceatannol inhibits melanogenesis by its antioxidative actions. Biol Pharm Bull 2007;30:2007-11. https://doi.org/10.1248/bpb.30.2007.

[143] Jeong ET, Jin MH, Kim MS, Chang YH, Park SG. Inhibition of melanogenesis by piceid isolated from Polygonum cuspidatum. Arch Pharm Res 2010;33:1331-8. https://doi.org/ 10.1007/s12272-010-0906-x.

[144] Uesugi D, Hamada H, Shimoda K, Kubota N, Ozaki SI, Nagatani N. Synthesis, oxygen radical absorbance capacity, and tyrosinase inhibitory activity of glycosides of resveratrol, pterostilbene, and pinostilbene. Biosci Biotechnol Biochem 2017;81:226-30. https://doi.org/10.1080/ 09168451.2016 .1240606$.

[145] Yanagihara M, Yoshimatsu M, Inoue A, Kanno T, Tatefuji T, Hashimoto $\mathrm{K}$. Inhibitory effect of gnetin $\mathrm{C}$, a resveratrol dimer from melinjo (Gnetum gnemon), on tyrosinase activity and melanin biosynthesis. Biol Pharm Bull 2012;35: 993-6. https://doi.org/10.1248/bpb.35.993.

[146] Yun CY, Ko SM, Choi YP, Kim BJ, Lee J, Kim JM, Kim JY, Song JY, Kim SH, Hwang BY, Hong JT, Han SB, Kim Y. $\alpha$ Viniferin improves facial hyperpigmentation via accelerating feedback termination of cAMP/PKA-signaled phosphorylation circuit in facultative melanogenesis. Theranostics 2018;8:2031-43. https://doi.org/10.7150/ thno. 24385 .

[147] Lee TH, Kang JH, Seo JO, Baek SH, Moh SH, Chae JK, Park YU, Ko YT, Kim SY. Anti-melanogenic potentials of nanoparticles from calli of resveratrol-enriched rice against UVB-induced hyperpigmentation in guinea pig skin. 
Biomol Ther 2016;24:85-93. https://doi.org/10.4062/ biomolther.2015.165.

[148] Rigon RB, Fachinetti N, Severino P, Santana MH, Chorilli M. Skin delivery and in vitro biological evaluation of transresveratrol-loaded solid lipid nanoparticles for skin disorder therapies. Molecules 2016;21:116. https://doi.org/ 10.3390/molecules21010116.

[149] Yeh YC, Huang TH, Yang SC, Chen CC, Fang JY. Nanobased drug delivery or targeting to eradicate bacteria for infection mitigation: a review of recent advances. Front Chem 2020;8:286. https://doi.org/10.3389/ fchem.2020.00286.

[150] Ong PY, Leung DY. Bacterial and viral infections in atopic dermatitis: a comprehensive review. Clin Rev Allergy Immunol 2016;51:329-37. https://doi.org/10.1007/s12016016-8548-5.

[151] Yang SC, Huang TH, Chiu CH, Chou WL, Alalaiwe A, Yeh YC, Su KW, Fang JY. The atopic dermatitis-like lesion and the associated MRSA infection and barrier dysfunction can be alleviated by 2,4-dimethoxy-6-methylbenzene-1,3-diol from Antrodia camphorata. J Dermatol Sci 2018;92:188-96. https://doi.org/10.1016/ j.jdermsci.2018.09.002.

[152] Chan MM. Antimicrobial effect of resveratrol on dermatophytes and bacterial pathogens of the skin. Biochem Pharmacol 2002;63:99-104. https://doi.org/10.1016/s00062952(01)00886-3.

[153] Mattio LM, Catinella G, Pallavalles S, Pinto A. Stilbenoids: a natural arsenal against bacterial pathogens. Antibiotics 2020;9:336. https://doi.org/10.3390/antibiotics9060336.
[154] Annunziata G, Maisto M, Schisano C, Ciampaglia R, Narciso V, Tenore GC, Novellino E. Resveratrol as a novel anti-herpes simplex virus nutraceutical agent: an overview. Viruses 2018;10:473. https://doi.org/10.3390/ v10090473.

[155] Docherty JJ, Smith JS, Fu MM, Stoner T, Booth T. Effect of topically applied resveratrol on cutaneous herpes simplex virus infections in hairless mice. Antiviral Res 2004;61: 19-26. https://doi.org/10.1016/j.antiviral.2003.07.001.

[156] Chuanasa T, Phromjai J, Lipipun V, Likhitwitayawuid K, Suzuki M, Pramyothin P, Hattori M, Shiraki K. Anti-herpes simplex virus (HSV-1) activity of oxyresveratrol derived from Thai medicinal plant: mechanism of action and therapeutic efficacy on cutaneous HSV-1 infection in mice. Antiviral Res 2008;80:62-70. https://doi.org/10.1016/ j.antiviral.2008.05.002

[157] Yang SC, Tseng CH, Wang PW, Lu PL, Weng YH, Yen FL, Fang JY. Pterostilbene, a methoxylated resveratrol derivative, efficiently eradicates planktonic, biofilm, and intracellular MRSA by topical application. Front Microbiol 2017;8: 1103. https://doi.org/10.3389/fmicb.2017.01103.

[158] Vitonyte J, Manca ML, Caddeo C, Valenti D, Peris JE, Usach I, Nacher A, Matos M, Gutiérrez G, Orrù G, FernàndezBusquets X, Fadda AM, Manconi M. Biofunctional viscous nanovesicles co-loaded with resveratrol and gallic acid for skin protection against microbial and oxidative injuries. Eur J Pharm Biopharm 2017;114:278-87. https://doi.org/10.1016/ j.ejpb.2017.02.004. 